\title{
A community-based lifestyle and weight loss intervention promoting a Mediterranean-style diet pattern evaluated in the stroke belt of North Carolina: the Heart Healthy Lenoir Project
}

Thomas C. Keyserling ${ }^{1,2^{*}}$, Carmen D. Samuel-Hodge ${ }^{2,4}$, Stephanie Jilcott Pitts ${ }^{3}$, Beverly A. Garcia ${ }^{2}$, Larry F. Johnston², Ziya Gizlice ${ }^{2}$, Cassandra L. Miller ${ }^{2}$, Danielle F. Braxton ${ }^{2,4}$, Kelly R. Evenson ${ }^{5}$, Janice C. Smith², Gwen B. Davis ${ }^{2}$, Emmanuelle L. Quenum ${ }^{6}$, Nadya T. Majette Elliott ${ }^{7}$, Myron D. Gross ${ }^{8}$, Katrina E. Donahue ${ }^{9}$, Jacqueline R. Halladay ${ }^{9,10}$ and Alice S. Ammerman ${ }^{2,4}$

\begin{abstract}
Background: Because residents of the southeastern United States experience disproportionally high rates of cardiovascular disease (CVD), it is important to develop effective lifestyle interventions for this population.

Methods: The primary objective was to develop and evaluate a dietary, physical activity (PA) and weight loss intervention for residents of the southeastern US. The intervention, given in eastern North Carolina, was evaluated in a 2 year prospective cohort study with an embedded randomized controlled trial (RCT) of a weight loss maintenance intervention. The intervention included: Phase I (months 1-6), individually-tailored intervention promoting a Mediterranean-style dietary pattern and increased walking; Phase II (months 7-12), option of a 16-week weight loss intervention for those with $\mathrm{BMI} \geq 25 \mathrm{~kg} / \mathrm{m}^{2}$ offered in 2 formats (16 weekly group sessions or 5 group sessions and 10 phone calls) or a lifestyle maintenance intervention; and Phase III (months 13-24), weight loss maintenance RCT for those losing $\geq 8 \mathrm{lb}$ with all other participants receiving a lifestyle maintenance intervention. Change in diet and PA behaviors, CVD risk factors, and weight were assessed at 6, 12, and 24 month follow-up.

(Continued on next page)
\end{abstract}

\footnotetext{
*Correspondence: jato@med.unc.edu

'Division of General Medicine and Clinical Epidemiology, Department of Medicine, School of Medicine, CB 7110, University of North Carolina, 5039 Old Clinic Building, Chapel Hill, NC 27599, USA

${ }^{2}$ Center for Health Promotion and Disease Prevention (a CDC Prevention Research Center), CB 7426, University of North Carolina, Chapel Hill, NC 27599, USA

Full list of author information is available at the end of the article
} 
(Continued from previous page)

Results: Baseline characteristics ( $N=339)$ were: 260 (77 \%) females, 219 (65 \%) African Americans, mean age 56 years, and mean body mass index $36 \mathrm{~kg} / \mathrm{m}^{2}$. In Phase I, among 251 (74\%) that returned for 6 month follow-up, there were substantial improvements in diet score (4.3 units [95 \% Cl 3.7 to 5.0]), walking (64 min/week [19 to 109]), and systolic blood pressure $(-6.4 \mathrm{mmHg}[-8.7$ to -4.1$])$ that were generally maintained through 24 month follow-up. In Phase II, 138 (57 group only, 81 group/phone) chose the weight loss intervention and at 12 months, weight change was: -3 . $1 \mathrm{~kg}(-4.9$ to -1.3$)$ for group ( $N=50)$ and $-2.1 \mathrm{~kg}(-3.2$ to -1.0$)$ for group/phone combination $(N=75)$. In Phase III, 27 participants took part in the RCT. At 24 months, weight loss was $-2.1 \mathrm{~kg}(-4.3$ to 0.0$)$ for group $(N=51)$ and $-1.1 \mathrm{~kg}$ ( -2.7 to 0.4$)$ for combination $(N=72)$. Outcomes for African American and whites were similar.

Conclusions: The intervention yielded substantial improvement in diet, PA, and blood pressure, but weight loss was modest.

Trial registration: clinicaltrials.gov Identifier: NCT01433484

Keywords: Mediterranean diet, Dietary intervention, Lifestyle intervention, Weight loss intervention, Low-income participants, Disparities, Cardiovascular disease, Prevention

\section{Background}

In the United States (US), large disparities in cardiovascular disease (CVD) exist among subgroups defined by race, ethnicity, socioeconomic status (SES), and geography (with rates high in the Southeast, particularly in the "stroke belt") [1-6]. The reasons are complex and include differences in genetic factors, access to and quality of care $[7,8]$, and lifestyle factors $[5,6]$. Notably, individuals of low SES and minority status, and more generally, residents of the southeastern US, typically consume less fruit and vegetables [9-12], engage in less leisure-time physical activity (PA) [13, 14], and are more likely to be obese [15] compared to higher SES, nonminority, and non-southeastern counterparts. As diet and PA behaviors are modifiable and, if sustained, are associated with substantial reduction in CVD risk $[16,17]$, improving diet and PA behaviors in high risk groups affords an opportunity to substantially reduce CVD disparities.

Dietary patterns that include frequent consumption of high quality fats (polyunsaturated and monounsaturated fats primarily from plant sources and fish) and carbohydrates (fruits, vegetables, and whole grains) are associated with large reductions in CVD risk [16, 18, 19]. In the PREDIMED randomized trial [20], a Mediterranean dietary pattern supplemented with nuts or olive oil reduced CVD risk by $30 \%$ in the intervention groups. While the Mediterranean dietary pattern has been well studied in Europe [21-23] and in selected US populations [24-28], it has not been evaluated in high risk, largely minority populations in the southeastern US. Further, the Mediterranean dietary pattern holds promise for weight loss interventions as it may be easier to maintain over time, especially compared to low fat diets [29].

Given the importance of dietary patterns in reducing CVD risk [30], and the burden of CVD risk among residents of the "stroke belt" in eastern North Carolina [4], we developed and evaluated a culturally appropriate lifestyle intervention for this population, with a major focus on improving diet quality while also promoting PA and weight loss. In this paper we report the intervention's effect on diet and PA behaviors, CVD risk factors, and weight loss through 24 months of follow-up. Because a major focus of this research was to reduce disparities in CVD risk, outcomes are also reported by race, as African Americans are at increased risk for CVD [3], but often have poorer outcomes compared to whites in response to lifestyle and weight loss interventions [31-34].

\section{Methods}

\section{Study overview}

Situated in eastern North Carolina, Lenoir County is located in the "stroke belt," [4] with elevated heart disease and stroke rates relative to other regions of North Carolina [35] and national levels [36]. This study was part of the Heart Healthy Lenoir (HHL) Project [37], a collaborative research effort designed to reduce CVD risk and disparities in risk in Lenoir County. This paper reports on the lifestyle intervention study, one of 3 coordinated HHL studies which also included a study to improve high blood pressure (BP) management at local practices and a study examining associations between genetic markers and change in CVD risk factors. Lifestyle study participants were recruited from the community and also included some participants who took part in the HHL high BP study [38]. The study was designed and conducted with input from a local Community Advisory Committee (CAC) [37] with data collected from September 20, 2011 to November 7, 2014 and analyzed in 2015 and 2016. 
The lifestyle study included 3 phases, as depicted in Fig. 1. Phase I, lasting 6 months and given to all participants, focused on improving diet quality and increasing PA. In Phase II, also 6 months in length, participants with a body mass index $(\mathrm{BMI}) \geq 25 \mathrm{~kg} / \mathrm{m}^{2}$ were invited to take part in a weight loss intervention. Those who did not and those with a $\mathrm{BMI}<25 \mathrm{~kg} / \mathrm{m}^{2}$ received a lifestyle maintenance intervention. Phase III, lasting a year, included a randomized controlled trial (RCT) comparing a more intensive to less intensive weight loss maintenance intervention for those who lost $\geq 8 \mathrm{lb}$ in Phase II and a lifestyle maintenance intervention for the other participants. We did not include a control group in Phases I and II because we had previously shown lifestyle and weight loss interventions given in similar formats to low SES participants were effective when evaluated in randomized trials [39-42] and we wanted to offer a lifestyle and weight loss interventions to as many community members as possible. Additionally, our CAC strongly encouraged a study design in which all participants received "active treatment."

\section{Participants}

The enrollment goal for the lifestyle study was 350 participants; approximately 150 enrolled from the community and 200 from the high BP study. The rational for including BP study participants was their increased risk for CVD and likelihood of benefit from receiving the lifestyle intervention. To recruit from the community, the study was publicized through flyers, newspaper articles, television notices, word of mouth, and the study website. In an effort to enroll a representative community sample, the only inclusion criteria for screening were age $\geq 18$ years and interest in improving diet and PA behaviors to reduce CVD risk. Screening criteria for the high BP study were age $\geq 18$, established patient at a participating practice, and a systolic $\mathrm{BP} \geq 150 \mathrm{mmHg}$ when assessed during routine care within the past 12 months. Participants who attended the enrollment

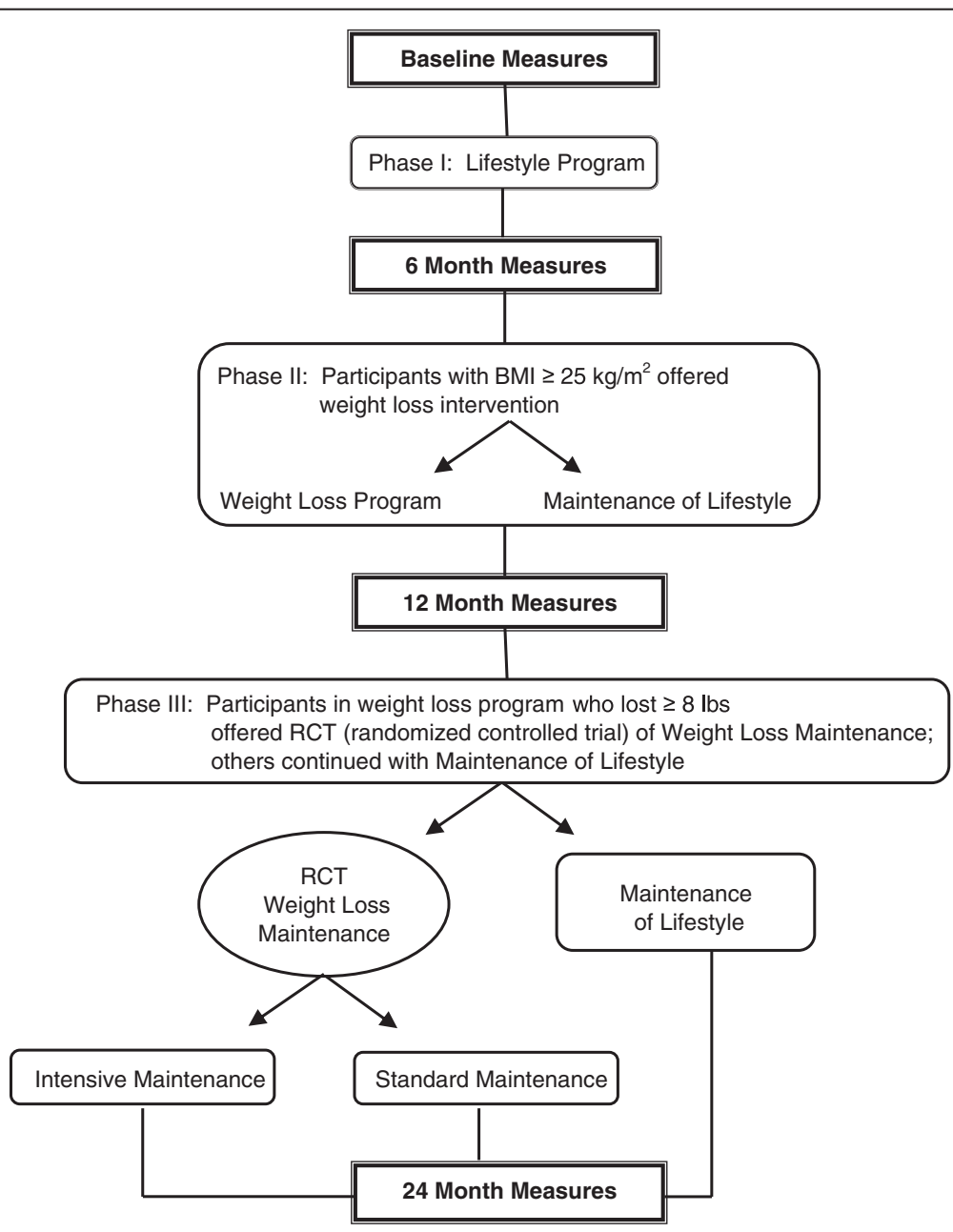

Fig. 1 Study overview 
visit for the high BP study were invited to take part in the lifestyle study until 200 agreed to do so.

Research staff screened potential participants (primarily by phone) to determine if they met the following additional eligibility criteria: lived in or near Lenoir County, North Carolina; spoke English; had access to a telephone; no drug or alcohol abuse within the past two years; did not have advanced kidney disease or dementia; did not have psychosis; and did not have a history of malignancy, other than non-melanoma skin cancer, unless surgically cured $>5$ years ago or in remission. If so, they were invited to the enrollment visit, conducted at a central research office or the participants' clinics. To identify potential safety issues related to increasing PA, a modified version of the Physical Activity Readiness Questionnaire [43] was given. Those who screened positive or had a myocardial infarction during the preceeding 3 months were required to get approval from their physician to take part in the PA component of the intervention.

\section{Lifestyle study intervention Phase I (months 1-6) diet and PA intervention}

The lifestyle study intervention focused on dietary and PA behaviors and did not address other aspects of lifestyle relevant to CVD risk reduction, such as smoking cessation. The intervention framework was originally developed by Ammerman and colleagues [44, 45], tested in a variety of clinical settings in North Carolina [46-48], and was previously updated to include a greater focus on carbohydrate quality [39]. To be consistent with the evolving literature on the importance of high quality fats in reducing CVD risk [49-56], the intervention was further revised for this study to include a major focus on improving fat quality. With this modification, the intervention dietary pattern closely resembled that tested in the nut intervention arm of the PREDIMED study; thus, we call it the "Med-South Diet," given the focus on the Southeastern US. As shown in Table 1, 9 of the 13 major recommendations advocated by the PREDIMED intervention diet [20] were almost identical to those in the Med-South Diet.

The Phase I intervention, described in detail in Section 1a of Additional file 1, included 4 monthly sessions delivered by a trained counselor. Dietary counseling comprised about $3 / 4$ of intervention content and time; the rest was devoted to PA counseling, with a goal of walking $\geq 7,500$ steps/day or $\geq 30 \mathrm{~min}$ on at least 5 days/week. Participants could choose the intervention format - either 60-min individual counseling sessions or 120 -min group sessions $[57,58]$ - which were given at a central research office or the participants' clinics for those also enrolled in the high BP study. Spouses and friends were invited to intervention sessions and for those who could not attend in person, counseling was offered by telephone. Participants also received an illustrated guide listing local community resources for healthy eating and PA and a pedometer and activity logs for self-monitoring PA.

At the first counseling session, the lifestyle survey (Section 1b of Additional file 1) was administered, consisting of the Dietary Risk Assessment (DRA), describe in detail below and 11 items assessing the amount and intensity of PA. Then, an overview of the program was given and the specific dietary content of Session 1 was reviewed. At the end of the session, the participant and counselor developed an individually tailored action plan to help guide the participant's eating behaviors for the next month (or until the next counseling session). To do so, they first reviewed the lifestyle survey page for Session 1 (Section 1b of Additional file 1, page A-3) and identified current eating behaviors that "could be improved" or "need to be improved." Then they reviewed the dietary tips for these problematic eating behaviors on the tip sheet for Session 1 (Section 1c of Additional file 1, page B-24), with tips linked by number and color coding to the items on the lifestyle survey. Of note, the tip sheet included recipe suggestions in a "Southern Style" cookbook given to all participants. Finally, the counselor and participant identified 2 achievable goals (participants could opt to choose 1) to work on before the next visit and documented them on the goal sheet (Section 1d of Additional file 1, page B-28). If time permitted during Session 1, PA was also addressed in a similarly tailored way but with only one goal selected. Subsequent sessions followed the same format but opened with a check-in on progress toward goals and addressed diet and PA.

\section{Phase II (months 7-12)-weight loss and lifestyle maintenance intervention}

Participants with a BMI $\geq 25 \mathrm{~kg} / \mathrm{m}^{2}$ could elect to take part in the weight loss intervention; those who did not and those with a BMI of $<25 \mathrm{~kg} / \mathrm{m}^{2}$ received a lifestyle maintenance intervention consisting of 3 phone calls, as previously described [59]. The weight loss intervention was offered in 2 formats over approximately 16 weeks: weekly group sessions (16) as previously tested [40, 41, 60], or 5 group sessions plus 10 phone contacts (combination intervention) as outlined in Section 2 of Additional file 1. The major modification from the previously tested weight loss intervention was the focus on the Med-South dietary pattern and addition of newer evidence-based behavioral components (e.g., daily self-weighing) [61].

\section{Phase III (months 13-24)- weight loss and lifestyle maintenance interventions}

Participants losing $\geq 8 \mathrm{lb}$ could elect to take part in the weight loss maintenance RCT; those who did not and all 
Table 1 PREDIMED Diet goals ${ }^{20}$ compared to Med-South Diet goals $^{a}$

\begin{tabular}{|c|c|c|}
\hline Food & PREDIMED Diet goal & Med-South Diet goal \\
\hline 1-Vegetable Oil & $\begin{array}{l}\text { Olive oil group: } \geq 4 \\
\text { tbsp/day extra virgin olive oil }\end{array}$ & $\begin{array}{l}\text { 2-6 servings/day of foods high in healthy fats } \\
\text { (nuts, fish, full fat salad dressings and spreads, } \\
\text { other foods prepared with olive or vegetable } \\
\text { oils, and vegetables with high fat content such } \\
\text { as avocado) }\end{array}$ \\
\hline 2-Tree nuts and peanuts & Nut group: $\geq 3$ servings $/$ wk ${ }^{b}$ & $\geq 3$ servings $/ w k$ \\
\hline 3-Fresh fruits & $\geq 3$ servings/day & $\geq 7$ servings for fruits and vegetables/day \\
\hline 4-Vegetables & $\geq 3$ servings/day & \\
\hline 5-Fish (especially fatty fish), seafood & $\geq 3$ servings/wk & $\geq 1$ servings/wk \\
\hline 6-Legumes & $\geq 3$ servings/wk & $\geq 3$ servings/wk \\
\hline 7-Sofrito ${ }^{b}$ & $\geq 2$ servings/wk & No recommendation \\
\hline 8-White meat & Instead of red meat & Consume poultry often \\
\hline $\begin{array}{l}\text { 9-Wine with meals (optional, } \\
\text { only for habitual drinkers) }\end{array}$ & $\geq 7$ glasses $/ w k$ & $\begin{array}{l}\text { Do not recommend starting wine consumption, } \\
\text { but provide information on effects of alcohol for } \\
\text { heart health, suggesting up to } 1 \text { serving a day } \\
\text { for females and up to } 2 \text { for males }\end{array}$ \\
\hline 10-Soda drinks & $<1$ drink/day & $<1$ drink/day \\
\hline $\begin{array}{l}\text { 11-Commercial bakery goods, } \\
\text { sweets, and pastries }\end{array}$ & $<3$ servings/wk & $<3$ servings/wk \\
\hline 12-Spread fats & $<1$ serving/day & $\begin{array}{l}\text { Up to several servings/day of trans fat } \\
\text { free spreads }\end{array}$ \\
\hline 13-Red and processed meats & $<1$ serving/day & $\leq 1$ serving/day \\
\hline
\end{tabular}

Abbreviations: PREDIMED Prevención con Dieta Mediterránea, tbsp tablespoon, wk week

${ }^{a}$ Rows in italics indicate identical or nearly identical dietary recommendations

${ }^{b}$ The PREDIMED intervention recommended nuts daily, but considered nut consumption $\geq 3$ servings/wk to be adherent to the nut recommendation

'Sofrito is a sauce made with tomato and onion, often including garlic and aromatic herbs, and slowly simmered with olive oil

other study participants received brief, quarterly lifestyle maintenance intervention phone calls. The first 2 calls addressed diet and PA and, to tailor counseling, began with the counselor administering a subset of items from the lifestyle survey. The 3rd and 4th calls were openended, allowing the participant to select a diet or PA topic for discussion. For the weight loss maintenance RCT, participants were randomized with a 1:1 allocation ratio to receive either 36 phone contacts (weekly during months 1-6 and biweekly during months $7-12$ ), or 18 phone contacts (biweekly during months $1-6$, and monthly during months 7-12) as described in Section 3 of Additional file 1.

\section{High BP study intervention}

The HHL high BP study [38] used a community based participatory research (CBPR) approach in local primary care practices to design and test a multilevel intervention with both a practice and patient component. The overall goal was to improve $\mathrm{BP}$ control rates and narrow disparities in systolic BP control between African Americans and Whites and those with lower and higher health literacy. At the practice level, providers and staff were engaged during intervention development and collaborated with the research team to design practice quality improvement strategies including: monthly design team calls, 10 regional dinner meetings to improve office-based BP management, on-site practice facilitation to guide practice change, embedding principles of health literacy in intervention processes and patient educational materials, and reviewing electronic health record hypertension performance data.

The patient component included a prospective cohort study enrolling 525 adults receiving care at these practices, 200 of whom also took part in the HHL lifestyle study. At the enrollment visit, participants received a BP monitor (Omron Model BP 785 or Omron BP 653 wrist monitor), were asked to record BP 3 times weekly, and received monthly 15-min phone coaching calls for a year. The coaches used scripted healthy lifestyle and hypertension management information, motivational interviewing techniques, and goal setting strategies to promote behavioral change. Curriculum topics covered: stress management, alcohol and tobacco use, healthy eating, PA, patient/provider interaction, medication adherence, and weight loss as previously described [38]. After each phone coaching session, a short session summary was faxed to the primary care provider. Of note, the phone coaching component of the high BP study began almost 6 months after the lifestyle study intervention such that only 13 participants in the 
lifestyle study received coaching phone calls before the 6 month follow-up visit.

\section{Measures}

Outcome measures were assessed at baseline and 6, 12, and 24 month follow-up visits (except as noted). Previously validated questionnaires were administered addressing overall diet quality (DRA) [44,62], fruit and vegetable intake [63], dietary fat quality [64], PA, [65, 66] and quality of life (SF-12 instrument, Quality Metric, Inc., Lincoln, RI). The DRA is a 26 item food frequncy questionnaire: each item contributes a score of 0,1 , or 2 , which are summed for the total score, with range of 0-52. Similarly, the dietary fat quality questionnaire is comprized of 15 items: 3 about type of margarine are not scored with 12 scored as 0,1 , or 2 , summed for a total score ranging from 0 to 24 . Weight, as the average of two measures, was assessed in pounds to the nearest tenth by electronic scale (Seca 874, Seca, Hanover, MD) and height, measured at baseline only, was assessed with a portable stadiometer (Weigh and Measure, LLC, Olney, MD). After being seated for $5 \mathrm{~min}, 3$ automated BP measurements were obtained (Omron HEM-907XL, Omron Healthcare, Lake Forest, IL) at $60 \mathrm{~s}$ intervals and averaged. Total and highdensity lipoprotein cholesterol (HDL-C) were assessed at baseline, 12, and 24 months by enzymatic methods

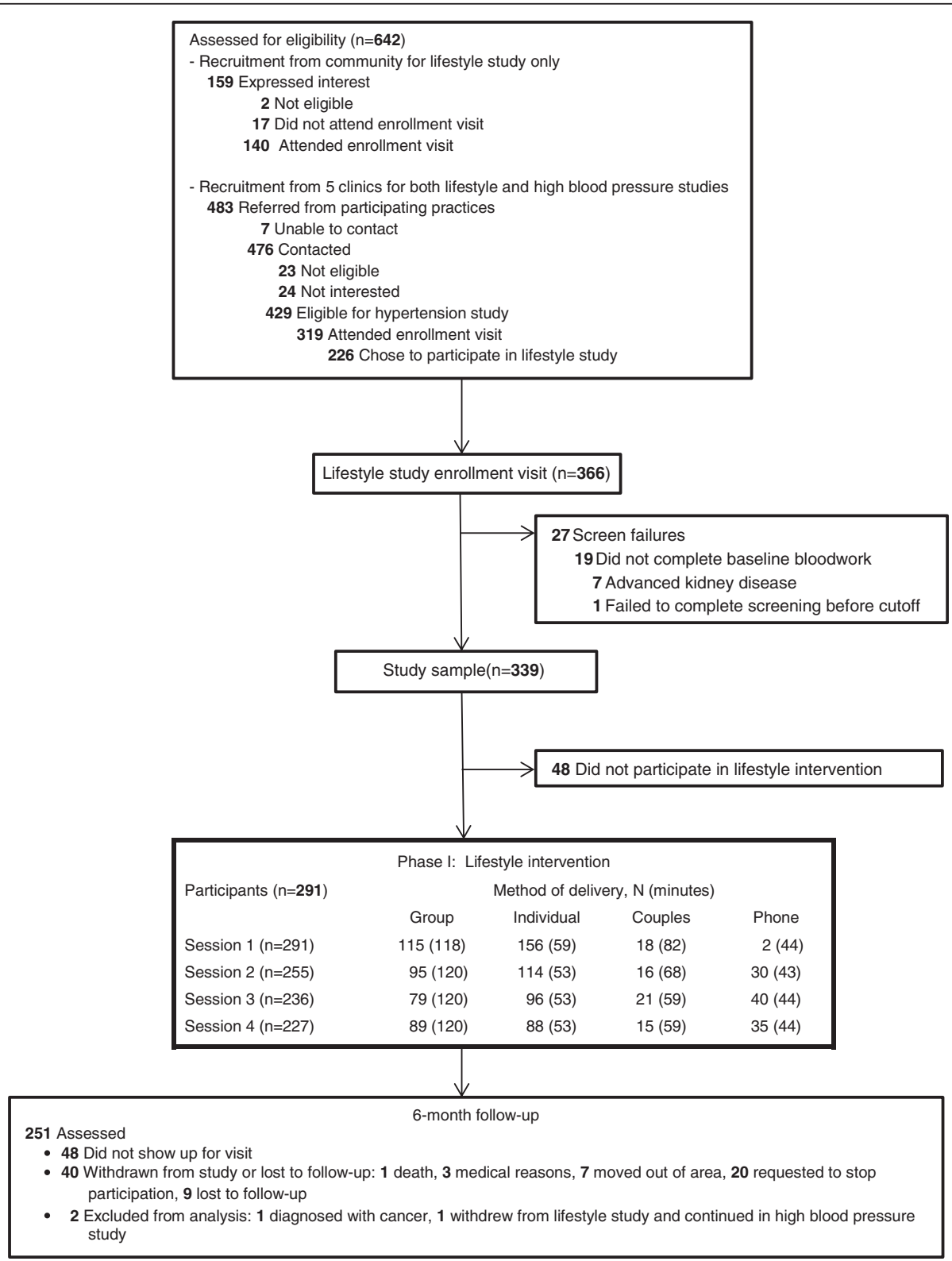

Fig. 2 Study flow diagram, part 1 
Table 2 Baseline characteristics: overall, by race, and by intervention group ${ }^{a}$

\begin{tabular}{|c|c|c|c|c|c|c|}
\hline \multirow[t]{4}{*}{ Characteristics } & \multirow{4}{*}{$\begin{array}{l}\text { Overall } \\
n=339\end{array}$} & \multicolumn{2}{|l|}{ Race $^{\text {b }}$} & \multicolumn{3}{|c|}{ Participant selected intervention group ${ }^{c}$} \\
\hline & & African & White & Lifestyle & Weight & Weight loss, \\
\hline & & \multicolumn{2}{|l|}{ American } & & loss, group & combination \\
\hline & & $n=219$ & $n=117$ & $n=160$ & $n=57$ & $n=81$ \\
\hline \multicolumn{7}{|l|}{ Demographics } \\
\hline Age, mean (SE) & $56(0.6)$ & $54(0.8)$ & $58(1.0)$ & $57(1.0)$ & $53(1.3)$ & $55(1.1)$ \\
\hline Female sex & $260(77)$ & $181(83)$ & $76(65)$ & $110(69)$ & $52(91)$ & $72(89)$ \\
\hline \multicolumn{7}{|l|}{ Race } \\
\hline African American & & & & $101(63)$ & $41(72)$ & $62(79)$ \\
\hline White & & & & $58(37)$ & $16(28)$ & $17(21)$ \\
\hline \multicolumn{7}{|l|}{ Education, y } \\
\hline$\leq 8$ (middle school or less) & $16(5)$ & $11(5)$ & $5(4)$ & $11(7)$ & $1(2)$ & $2(3)$ \\
\hline 9-11 (some high school) & $45(13)$ & $35(16)$ & $9(8)$ & $27(17)$ & $5(9)$ & $9(11)$ \\
\hline 12 (high school graduate) & $128(38)$ & $94(43)$ & $34(29)$ & $60(37)$ & $20(35)$ & $33(41)$ \\
\hline 13-15 (some college) & $79(23)$ & $45(21)$ & $33(28)$ & $35(22)$ & $15(26)$ & $18(22)$ \\
\hline 16 (college graduate) & $49(14)$ & $26(12)$ & $22(19)$ & $17(11)$ & $11(19)$ & $13(16)$ \\
\hline > 16 (graduate school) & $22(7)$ & $8(4)$ & $14(12)$ & $10(6)$ & $5(9)$ & $6(7)$ \\
\hline Education: high school or less & $189(56)$ & $140(64)$ & $48(41)$ & $98(61)$ & $26(46)$ & $44(54)$ \\
\hline \multicolumn{7}{|l|}{ Marital status } \\
\hline Married or living with a partner & $159(47)$ & $82(37)$ & $76(65)$ & $69(43)$ & $23(40)$ & $41(51)$ \\
\hline Other & $180(53)$ & $137(63)$ & $41(35)$ & $91(57)$ & $34(60)$ & $40(49)$ \\
\hline Currently have health insurance & $251(74)$ & $156(71)$ & $92(79)$ & $117(73)$ & $45(79)$ & $58(72)$ \\
\hline \multicolumn{7}{|l|}{ Current employment } \\
\hline Working full time & $124(37)$ & $82(37)$ & $40(34)$ & $46(29)$ & $29(51)$ & $38(47)$ \\
\hline Working part time & $42(12)$ & $31(14)$ & $10(8)$ & $23(14)$ & $4(7)$ & $10(12)$ \\
\hline Do not work due to health reasons & $69(20)$ & $43(20)$ & $26(22)$ & $37(23)$ & $9(16)$ & $16(20)$ \\
\hline Retired & $53(16)$ & $26(12)$ & $27(23)$ & $29(18)$ & $7(12)$ & $8(10)$ \\
\hline Other & $51(15)$ & $37(17)$ & $14(12)$ & $25(16)$ & $8(14)$ & $9(11)$ \\
\hline \multicolumn{7}{|l|}{ Annual household income } \\
\hline$<\$ 10,000$ & $62(20)$ & $50(26)$ & $11(10)$ & $40(29)$ & $6(11)$ & $9(11)$ \\
\hline$\$ 10,000$ to $<\$ 20,000$ & $64(21)$ & $45(23)$ & $19(17)$ & $29(21)$ & $11(21)$ & $18(23)$ \\
\hline$\$ 20,000$ to $<\$ 40,000$ & $84(28)$ & $60(31)$ & $23(21)$ & $32(24)$ & $14(26)$ & $27(35)$ \\
\hline$\$ 40,000$ to $<\$ 60,000$ & $33(11)$ & $15(8)$ & $18(17)$ & $11(8)$ & $8(15)$ & $9(11)$ \\
\hline$\$ 60,000$ to $<\$ 80,000$ & $27(9)$ & $13(7)$ & $14(13)$ & $11(8)$ & $11(21)$ & $5(6)$ \\
\hline$\geq \$ 80,000$ & $34(11)$ & $10(5)$ & $24(22)$ & $13(10)$ & $3(6)$ & $10(13)$ \\
\hline \multicolumn{7}{|l|}{ CVD and risk factors for CVD } \\
\hline Known coronary heart disease & $49(14)$ & $30(14)$ & $19(16)$ & $29(18)$ & $5(9)$ & $5(6)$ \\
\hline Known CVD & $62(18)$ & $37(17)$ & $25(21)$ & $34(21)$ & $7(12)$ & $8(10)$ \\
\hline Hypertension & $291(86)$ & $195(89)$ & $95(81)$ & $143(89)$ & $47(82)$ & $66(81)$ \\
\hline \multicolumn{7}{|l|}{ Cholesterol category } \\
\hline High ( $\geq 240$ mg/dL) & $187(56)$ & $110(51)$ & $76(65)$ & $88(56)$ & $31(55)$ & $47(59)$ \\
\hline Borderline (200-239 mg/dL) & $46(14)$ & $33(15)$ & $12(10)$ & $16(10)$ & $11(19)$ & $13(16)$ \\
\hline Desirable (<200 mg/dL) & $102(30)$ & $72(33)$ & $29(25)$ & $54(34)$ & $15(26)$ & $20(25)$ \\
\hline Diabetes & $124(37)$ & $89(41)$ & $34(29)$ & $62(39)$ & $21(37)$ & $27(33)$ \\
\hline Current cigarette smoker & $54(16)$ & $37(17)$ & $17(14)$ & $36(22)$ & $4(7)$ & $5(6)$ \\
\hline
\end{tabular}


Table 2 Baseline characteristics: overall, by race, and by intervention group ${ }^{a}$ (Continued)

\begin{tabular}{|c|c|c|c|c|c|c|}
\hline $\begin{array}{l}\text { Packs of cigarettes smoked per day, } \\
\text { mean (SE) for current smokers }\end{array}$ & $0.7(0.1)$ & $0.6(0.1)$ & $0.9(0.1)$ & $0.7(0.1)$ & $0.6(0.2)$ & $0.6(0.3)$ \\
\hline Taking BP lowering medication & $260(77)$ & $176(80)$ & $83(71)$ & $129(81)$ & $43(75)$ & $60(74)$ \\
\hline \multicolumn{7}{|l|}{ Lifestyle mean (SE) } \\
\hline DRA total score & $27.8(0.3)$ & $28.0(0.5)$ & $27.6(0.4)$ & $27.8(0.5)$ & $27.2(0.7)$ & $27.6(0.6)$ \\
\hline Fat quality screener score & $15.5(0.2)$ & $15.4(0.2)$ & $15.07(0.3)$ & $15.4(0.2)$ & $15.3(0.3)$ & $15.4(0.3)$ \\
\hline Fruit and vegetable, servings per day & $3.4(0.1)$ & $3.4(0.1)$ & $3.5(0.2)$ & $3.5(0.2)$ & $3.0(0.3)$ & $3.5(0.2)$ \\
\hline Carotenoid index ${ }^{\mathrm{e}}$, mean (SE) & $40.7(1.3)$ & $41.9(1.6)$ & $38.2(2.5)$ & $41.1(2.0)$ & $42.1(3.5)$ & $39.1(2.4)$ \\
\hline Walking time, $\min / \mathrm{wk}^{\mathrm{f}}$ & $91(11.3)$ & $100(16.2)$ & $73(11.8)$ & $110(18.8)$ & $97(26.5)$ & $55(13.3)$ \\
\hline Activity time, $\mathrm{min} / \mathrm{wk}^{\mathrm{g}}$ & $149(14.0)$ & $150(18.2)$ & $143(21.5)$ & $160(22.7)$ & $148(29.1)$ & $135(25.7)$ \\
\hline \multicolumn{7}{|l|}{ Physiologic mean (SE) } \\
\hline Weight, kg & $98.1(1.4)$ & $100(1.7)$ & $94(2.3)$ & $93.8(2.0)$ & $101.3(3.3)$ & $106.4(2.6)$ \\
\hline $\mathrm{BMl}, \mathrm{kg} / \mathrm{m}^{2}$ & $36(0.5)$ & $37(0.6)$ & $34(0.8)$ & $34(0.7)$ & $38(1.1)$ & $40(1.0)$ \\
\hline Systolic BP, mm Hg & $135(1.2)$ & $136(1.6)$ & $132(1.8)$ & $138(1.8)$ & $130(2.6)$ & $133(2.3)$ \\
\hline LS study only $(n=139)$ & $125(1.3)$ & $126(1.6)$ & $122(2.2)$ & $124(2.5)$ & $126(2.7)$ & $126(2.0)$ \\
\hline LS and HBP study $(n=200)$ & $142(1.7)$ & $143(2.2)$ & $139(2.4)$ & $142(2.2)$ & $137(5.2)$ & $142(4.0)$ \\
\hline Diastolic BP, mm Hg & $82(0.7)$ & $83(0.9)$ & $80(1.0)$ & $83(1.0)$ & $82(1.4)$ & $81(1.3)$ \\
\hline LS study only $(n=139)$ & $79(0.8)$ & $80(1.0)$ & $76(1.4)$ & $77(1.5)$ & $80(1.5)$ & $79(1.5)$ \\
\hline LS and HBP study $(n=200)$ & $84(0.9)$ & $86(1.3)$ & $83(1.3)$ & $85(1.2)$ & $87(2.7)$ & $84(2.2)$ \\
\hline $\mathrm{HbA}_{1 c} \%$ of total $\mathrm{Hb}$ & $6.6(0.1)$ & $6.7(0.1)$ & $6.2(0.1)$ & $6.5(0.1)$ & $6.9(0.3)$ & $6.5(0.2)$ \\
\hline Total cholesterol, mg/dL & $193(2.3)$ & $191(2.8)$ & $196(4.0)$ & $191(3.1)$ & $198(6.0)$ & $189(4.7)$ \\
\hline HDL cholesterol, mg/dL & $54(0.8)$ & $57(1.0)$ & $50(1.4)$ & $55(1.2)$ & $53(1.8)$ & $53(1.5)$ \\
\hline
\end{tabular}

Abbreviations: $B M I$ body mass index, $B P$ blood pressure, $C V D$ cardiovascular disease, $D R A$ Dietary Risk Assessment, $H D L-C$ high-density lipoprotein, $H b A_{1 c}$ hemoglobin $A_{1 c}, H B P$ high blood pressure, $L S$ lifestyle, $S E$ standard error

Note: SI unit conversion factors: To convert all types of cholesterol to millimoles per liter, multiply by 0.0259

${ }^{a}$ Unless otherwise noted, data are reported as number (percentage) of participants

b 3 categorized as other race

c Participants selected intervention group at 6 month follow-up visit; if they did not attend this visit they were assigned to lifestyle group

${ }^{\mathrm{d}}$ Framingham risk scores calculated as percent chance of developing angina, having a myocardial infarction, or dying of coronary heart disease over a 10 year time frame

e Carotenoid index, calculated as the sum of $\alpha$-carotene, $\beta$-carotene, $\beta$-cryptoxanthin, and zeaxanthin. Data presented are for nonsmokers $(n=261)$. A higher index indicates greater fruit and vegetable consumption. Statistical tests performed on log-transformed data

${ }^{f}$ Includes walking for transportation and exercise

${ }^{\mathrm{g}}$ Includes walking and other moderate and vigorous activity

${ }^{\mathrm{h}}$ Systolic and diastolic blood pressure results are also presented for participants in LS study only and participants in both LS and HBP studies

(LabCorp, Burlington, NC). Blood carotenoids (Molecular Epidemiology and Biomarker Research Laboratory, University of Minnesota, Minneapolis, MN) [62] were assessed at baseline, 6, and 12 months, as previously described [59]. At each follow-up visit, participants were queried about adverse events. Participants received \$40 for enrollment, \$25 for 6 and 12 month visits, and $\$ 30$ for the 24 month visit.

\section{Sample size, randomization, and statistical analysis}

The enrollment goal of 350 participants was based on having a sufficient sample $(N=100)$ for the embedded RCT of weight loss maintenance, assuming $60 \%$ of study participants $(N=210)$ would choose to be in the weight loss intervention and $50 \%$ of those $(N=105)$ would lose $\geq 8 \mathrm{lb}$ [40]. An N of 100 in the RCT would provide $80 \%$ power to detect a weight difference of $2 \mathrm{~kg}$ between study groups. In addition, the overall sample of 350 was felt sufficient to describe the primary objective of the intervention, to improve diet quality at 6 month follow-up, and the major secondary objectives of improved diet quality, PA, and weight loss at 12 and 24 month follow-up.

Study sample characteristics were summarized using descriptive statistics. Participants who became pregnant, had bariatric surgery, or were diagnosed with cancer (excluding non-melanoma skin cancer or localized breast or prostate cancer diagnosed by screening tests) were not included in the analysis of outcomes. Otherwise, pre-post changes in study outcomes were assessed among returnees, by intervention group, and by race using paired t-tests for continuous outcomes and McNemar's tests for binary outcomes. The carotenoid index score was log-transformed for obtaining $p$-values 
Table 3 Change from baseline to 6 months ${ }^{a}$

\begin{tabular}{|c|c|c|}
\hline \multirow[t]{4}{*}{ Outcome } & \multicolumn{2}{|c|}{ Phase 1} \\
\hline & \multicolumn{2}{|c|}{ Baseline to 6 months } \\
\hline & \multicolumn{2}{|c|}{ (6 months minus baseline) } \\
\hline & $n$ & Mean, $95 \% \mathrm{Cl}$ \\
\hline \multicolumn{3}{|l|}{ Dietary } \\
\hline \multicolumn{3}{|l|}{ DRA total score } \\
\hline All & 235 & $4.3(3.7 \text { to } 5.0)^{* * *}$ \\
\hline \multicolumn{3}{|l|}{ Subgroup by race ${ }^{b}$} \\
\hline -African American & 155 & $4.6(3.7 \text { to } 5.5)^{* * *}$ \\
\hline -White & 77 & $3.9(2.9 \text { to } 5.0)^{* * *}$ \\
\hline \multicolumn{3}{|l|}{ Fat quality screener score } \\
\hline All & 229 & $1.4(1.0 \text { to } 1.7)^{* * *}$ \\
\hline -African American & 150 & $1.4(0.9 \text { to } 1.8)^{* * *}$ \\
\hline -White & 76 & $1.3(0.7 \text { to } 2.0)^{* * *}$ \\
\hline \multicolumn{3}{|c|}{ Fruit and vegetable servings per day } \\
\hline All & 249 & $0.3(0.1 \text { to } 0.5)^{* *}$ \\
\hline -African American & 168 & $0.2(0.0$ to 0.5$)$ \\
\hline -White & 78 & $0.3(0.0 \text { to } 0.7)^{*}$ \\
\hline \multicolumn{3}{|l|}{ Carotenoid index ${ }^{c}$} \\
\hline All & 169 & $-0.9(-3.3$ to 1.5$)$ \\
\hline -African American & 118 & $-0.2(-2.8$ to 2.5$)$ \\
\hline -White & 49 & $-3.5(-8.7$ to 1.8$)$ \\
\hline \multicolumn{3}{|l|}{ Physical Activity } \\
\hline \multicolumn{3}{|l|}{ Walking time, $\mathrm{min} / \mathrm{wk}^{\mathrm{d}}$} \\
\hline All & 249 & $64(19 \text { to } 109)^{* *}$ \\
\hline -African American & 168 & $65(5 \text { to } 125)^{*}$ \\
\hline -White & 78 & $66(4 \text { to } 128)^{*}$ \\
\hline \multicolumn{3}{|l|}{ Activity time, $\mathrm{min} / \mathrm{wk}^{\mathrm{e}}$} \\
\hline All & 249 & $97(36 \text { to } 158)^{* *}$ \\
\hline -African American & 168 & $106(28 \text { to } 184)^{* *}$ \\
\hline -White & 78 & $88(-13$ to 188$)$ \\
\hline \multicolumn{3}{|l|}{ Blood Pressure Medication } \\
\hline \multicolumn{3}{|c|}{ Taking BP lowering medication, \% } \\
\hline All & 249 & $2.0 \%(-0.3$ to 4.4$)$ \\
\hline -African American & 167 & $1.2 \%(-1.7$ to 4.1$)$ \\
\hline -White & 78 & $3.8 \%(-0.4$ to 8.1$)$ \\
\hline \multicolumn{3}{|l|}{ Physiologic } \\
\hline \multicolumn{3}{|l|}{ Systolic BP, mm Hg${ }^{f}$} \\
\hline LS study only & 119 & $-4.7(-6.9 \text { to }-2.6)^{* * *}$ \\
\hline LS and HBP study & 130 & $-7.9(-11.8 \text { to } 4.0)^{* * *}$ \\
\hline All & 249 & $-6.4(-8.7 \text { to }-4.1)^{* * *}$ \\
\hline -African American & 168 & $-6.8(-9.7 \text { to }-3.8)^{* * *}$ \\
\hline -White & 78 & $-5.6(-9.4 \text { to }-1.8)^{* *}$ \\
\hline
\end{tabular}


Table 3 Change from baseline to 6 months $^{\mathrm{a}}$ (Continued)

\begin{tabular}{|c|c|c|}
\hline \multicolumn{3}{|l|}{ Diastolic BP, mm Hg } \\
\hline LS study only & 119 & $-2.8(-4.2 \text { to }-1.3)^{* * *}$ \\
\hline LS and HBP study & 130 & $-4.6(-6.5 \text { to }-2.7)^{* * *}$ \\
\hline All & 249 & $-3.7(-4.9 \text { to }-2.5)^{* * *}$ \\
\hline -African American & 168 & $-3.5(-5.1 \text { to }-2.0)^{* * *}$ \\
\hline -White & 78 & $-4(-6.1 \text { to }-2.3)^{* * *}$ \\
\hline \multicolumn{3}{|l|}{ Weight, kg } \\
\hline All & 248 & $-0.7(-1.2 \text { to }-0.3)^{* *}$ \\
\hline -African American & 167 & $-0.8(-1.4 \text { to }-0.3)^{* *}$ \\
\hline -White & 78 & $-0.4(-1.3$ to 0.5$)$ \\
\hline \multicolumn{3}{|c|}{ Weight, $\geq 5 \%$ weight loss, $\%$} \\
\hline All & 248 & $9 \%(6$ to 13$)$ \\
\hline -African American & 167 & $12 \%$ (7 to 17 ) \\
\hline -White & 78 & $4 \%(0$ to 8$)$ \\
\hline
\end{tabular}

Abbreviations: $B P$ blood pressure, $C$ confidence interval, $D R A$ dietary risk assessment, $H B P$ high blood pressure, $L S$ lifestyle

Note: Boldface indicates statistical significance ${ }^{*} p \leq 0.05 ;{ }^{* *} p \leq 0.01 ;{ }^{* * *} p \leq 0.001$

a Data are means except where noted

b 3 categorized as other race

${ }^{c}$ Carotenoid index, calculated as the sum of a-carotene, $\beta$-carotene, $\beta$-cryptoxanthin, and zeaxanthin. Data presented are for nonsmokers and available only

through 12 month follow-up visit. A higher index indicates greater fruit and vegetable consumption. Statistical tests performed on log-transformed data

d Includes walking for transportation and exercise

e Includes walking and other moderate and vigorous activity

${ }^{f}$ Systolic and diastolic blood pressure results are also presented for participants in LS study only and participants in both LS and HBP studies

from paired t-tests. To explore predictors of change in $\mathrm{BP}$ at follow-up, we used linear regression models that assessed change in BP associated with change in diet, PA, and weight, while controlling for selected baseline characteristics. As the RCT turned out to be substantially under powered $(N=27)$, weight change for RCT participants are described, but statistical tests comparing outcomes by group were not performed. SAS version 9.3 (SAS Institute, Cary, NC) was used for analyses, with $p \leq .05$ considered statistically significant.

\section{Results}

Enrollment and baseline characteristics of participants

As depicted in Fig. 2, 339 participants completed baseline measures and comprised the study sample, with baseline characteristics presented in Table 2. The mean age was 56 years (range 18 to 92), 260 (77\%) were female, 219 (65 \%) were African American, 124 (37 \%) were employed full-time, 251 (74 \%) had health insurance, $210(62 \%)$ had an annual household income of $\leq \$ 40,000$ per year, 291 (86 \%) had hypertension, and the mean BMI was $36 \mathrm{~kg} / \mathrm{m}^{2}$. As anticipated, the mean baseline blood pressure was substantially higher in participants taking part in both the lifestyle and high BP study as compared to those only taking part in the lifestyle study. On average, African American participants were younger, less educated, had lower household income, and with the exception of HDL-C had more CVD risk factors.

\section{Phase I outcomes}

As outlined in Fig. 2, 291 (86 \%) participants attended the first intervention visit, with 115 (40\%) choosing group format, and the rest individual counseling. Overall, 237 (70 \%) completed all counseling sessions. As shown in Table 3, from baseline to 6 month follow-up, there were improvements in self-reported measures of diet quality (higher score indicates improved diet quality): DRA score increased 4.4 units (95\% CI 3.7 to 5.0$)$, fat quality score increased 1.4 units (1.0 to 1.7 ), and servings of fruit and vegetables per day increased by 0.3 (0.1 to 0.5$)$. In addition, there were increases in walking of $64 \mathrm{~min} /$ week (19 to 110 ) and total activity time (walking plus other types of moderate to vigorous PA) of $97 \mathrm{~min} /$ week (36 to 158). For physiologic outcomes, change in systolic BP was $-6.4 \mathrm{mmHg}(-8.7$ to -4.1$)$, diastolic BP $-3.7 \mathrm{mmHg}(-4.9$ to -2.5$)$, and weight $-0.7 \mathrm{~kg}(-1.2$ to -0.3$)$. Of note, there were significant reductions in systolic, $-4.7 \mathrm{mmHg}(-6.9$ to -2.6$)$ and diastolic, $-2.8 \mathrm{mmHg}(-4.2$ to -1.3$) \mathrm{BP}$ in the lifestyle only group. Among those who took part in both the lifestyle and high BP studies the systolic, $-7.9 \mathrm{mmHg}$ $(-11.8$ to 4.0$)$, and diastolic, $-4.6 \mathrm{mmHg}(-6.5$ to -2.7$)$, $\mathrm{BP}$ reductions were larger. In addition, desirable outcomes were similar or larger for African Americans compared to whites.

Of 242 participants completing the Phase I acceptability questionnaire, 170 (70 \%) strongly agreed and $66(27 \%)$ agreed with the following statement: "I would recommend 
the program to others." Similarly, 138 (57 \%) strongly agreed and $99(41 \%)$ agreed that "the information provided was easy to understand." In terms of diet counseling content, the information on nuts, spreads, dressings and oils was considered most helpful with 185 (76\%) indicating this session was very helpful and $43(18 \%)$ somewhat helpful.

\section{Phase II outcomes}

Figure 3 shows 298 (88\%) participants continued into Phase II: of these, 57 chose the group-based weight loss and 81 the combination format, with 160 receiving the lifestyle maintenance intervention (of these, 111 attended the 6 month measurement visit and 93 (84\%) had BMI $\geq 25 \mathrm{~kg} / \mathrm{m}^{2}$ but did not choose to be in the weight loss program). Change in outcomes from 6 to 12 and baseline to 12 months are shown in Tables 4 and 5 . Self-reported dietary changes were generally maintained through 12 months, but more so for the weight loss groups, especially for fruit and vegetable intake. From 6 to 12 months, the carotenoid index increased significantly for whites and from baseline to 12 months, there was a statistically significant increase in the carotenoid index score for all participants. The increase in PA reported from baseline to 6 months was generally maintained at 12 months, though less so for the group-based weight loss participants. Change in BP from baseline to 12 months among participants in the lifestyle only study was: systolic, $-1.4 \mathrm{mmHg}$ (-4.5 to 1.6$)$; diastolic $-2.0 \mathrm{mmHg}(-3.7$ to -0.4$)$. For those in both studies, it

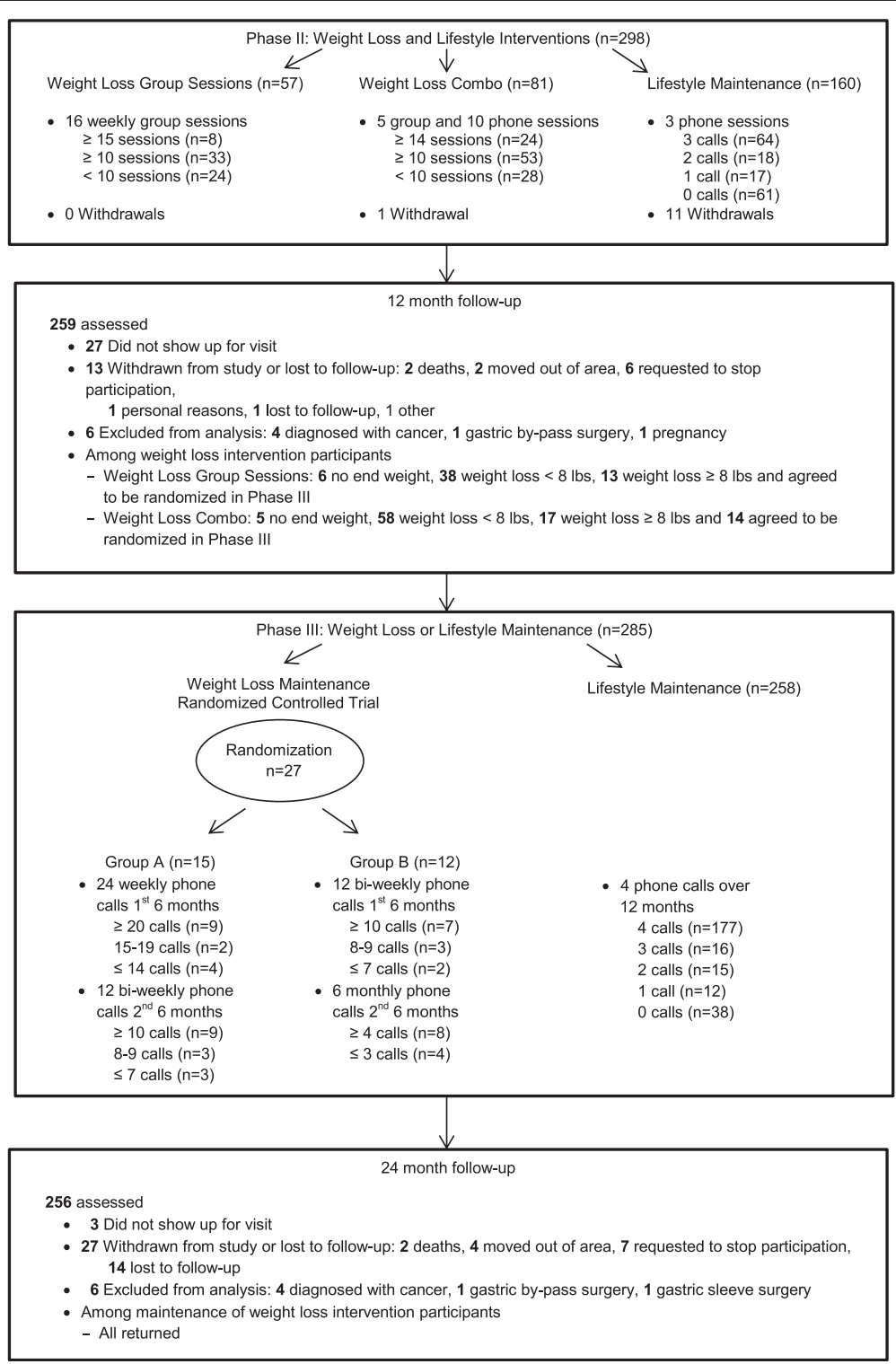

Fig. 3 Study flow diagram, part 2 
Table 4 Change in dietary and physical activity outcomes at 12 months ${ }^{a}$

\begin{tabular}{|c|c|c|c|c|}
\hline \multirow[t]{4}{*}{ Outcome } & \multicolumn{4}{|c|}{ Phase 2} \\
\hline & \multicolumn{2}{|c|}{6 months to 12 months } & \multicolumn{2}{|c|}{ Baseline to 12 months } \\
\hline & \multicolumn{2}{|c|}{ (12 months minus 6 months) } & \multicolumn{2}{|c|}{ (12 months minus baseline) } \\
\hline & $\mathrm{n}$ & Mean, $95 \% \mathrm{Cl}$ & $\mathrm{n}$ & Mean, $95 \% \mathrm{Cl}$ \\
\hline \multicolumn{5}{|l|}{ Dietary } \\
\hline \multicolumn{5}{|l|}{ DRA total score } \\
\hline All & 219 & $-0.7(-1.3 \text { to }-0.1)^{*}$ & 227 & $3.3(2.5 \text { to } 4.0)^{* * *}$ \\
\hline \multicolumn{5}{|l|}{ Subgroup by race ${ }^{b}$} \\
\hline -African American & 151 & $-0.2(-1.0$ to 0.6$)$ & 156 & $4.0(3.1 \text { to } 4.9)^{* * *}$ \\
\hline -White & 66 & $-1.9(-2.7 \text { to }-1.1)^{* * *}$ & 69 & $1.7(0.4 \text { to } 3.0)^{* *}$ \\
\hline \multicolumn{5}{|l|}{ Subgroup by intervention ${ }^{c}$} \\
\hline -Lifestyle & 93 & $0.0(-1.0$ to 0.9$)$ & 102 & $1.7(0.7 \text { to } 2.8)^{* * * *}$ \\
\hline -Wt loss, group & 51 & $-0.3(-1.5$ to 0.9$)$ & 51 & $5.1(3.8 \text { to } 6.4)^{* * * *}$ \\
\hline -Wt loss, combination & 75 & $-1.7(-2.8 \text { to }-0.7)^{* * *}$ & 74 & $4.1(2.7 \text { to } 5.6)^{* * * *}$ \\
\hline \multicolumn{5}{|l|}{ Fat quality screener score } \\
\hline All & 218 & $-0.1(-0.5$ to 0.2$)$ & 225 & $1.0(06 \text { to } 1.3)^{* * *}$ \\
\hline -African American & 150 & $0.1(-0.3$ to 0.5$)$ & 154 & $1.2(0.8 \text { to } 1.7)^{* * *}$ \\
\hline -White & 66 & $-0.6(-1.2 \text { to }-0.1)^{*}$ & 69 & $0.4(-0.2$ to 1.0$)$ \\
\hline -Lifestyle & 93 & $0.2(-0.4$ to 0.8$)$ & 102 & $0.7(0.1 \text { to } 1.2)^{*}$ \\
\hline$-W t$ loss, group & 51 & -0.1 ( -0.8 to 0.5$)$ & 48 & $1.3(0.6 \text { to } 2.0)^{* * *}$ \\
\hline -Wt loss, combination & 74 & $-0.6(-1.1 \text { to }-0.1)^{*}$ & 75 & $1.2(0.6 \text { to } 1.8)^{* * *}$ \\
\hline \multicolumn{5}{|c|}{ Fruit and vegetable servings per day } \\
\hline All & 221 & $0.4(0.2 \text { to } 0.5)^{* * *}$ & 253 & $0.5(0.3 \text { to } 0.8)^{* * * *}$ \\
\hline -African American & 153 & $0.5(0.2 \text { to } 0.7)^{* * *}$ & 178 & $0.5(0.2 \text { to } 0.9)^{* *}$ \\
\hline -White & 66 & $0.0(-0.3$ to 0.3$)$ & 73 & $0.5(0.1 \text { to } 0.9)^{* *}$ \\
\hline -Lifestyle & 95 & $0.1(-0.2$ to 0.4$)$ & 127 & $0.1(-0.2$ to 0.5$)$ \\
\hline -Wt loss, group & 51 & $0.5(0.1 \text { to } 0.9)^{*}$ & 51 & $1.0(0.5 \text { to } 1.5)^{* * * *}$ \\
\hline -Wt loss, combination & 75 & $0.6(0.2 \text { to } 0.9)^{* * *}$ & 75 & $0.9(0.4 \text { to } 1.3)^{* * *}$ \\
\hline \multicolumn{5}{|l|}{ Carotenoid index $^{\mathrm{d}}$} \\
\hline All & 105 & $3.7(0.4$ to 6.9$)$ & 117 & $3.1(-0.4 \text { to } 6.7)^{*}$ \\
\hline -African American & 77 & $3.1(-0.8$ to 7.1$)$ & 88 & $3.0(-1.4$ to 7.5$)$ \\
\hline -White & 27 & $5.6(-0.4 \text { to } 11.7)^{*}$ & 28 & $3.4(-2.0$ to 8.9$)$ \\
\hline -Lifestyle & 33 & $5.6(-0.2$ to 11.9$)$ & 40 & $3.1(-3.2$ to 9.5$)$ \\
\hline$-W t$ loss, group & 29 & $1.9(-3.5$ to 7.3$)$ & 31 & $3.7(-3.0$ to 10.4$)$ \\
\hline -Wt loss, combination & 43 & $3.2(-2.0$ to 8.4$)$ & 46 & $2.7(-2.9$ to 8.3$)$ \\
\hline \multicolumn{5}{|l|}{ Physical Activity } \\
\hline \multicolumn{5}{|l|}{ Walking time, $\mathrm{min} / \mathrm{wk}^{\mathrm{e}}$} \\
\hline All & 221 & 7 ( -49 to 63$)$ & 253 & $71(28 \text { to } 113)^{* * *}$ \\
\hline -African American & 153 & $16((-59$ to 91$)$ & 178 & $68(13 \text { to } 123)^{*}$ \\
\hline -White & 66 & $-14(-88$ to 61$)$ & 73 & $82(23 \text { to } 142)^{* *}$ \\
\hline -Lifestyle & 95 & $29(-56$ to 113$)$ & 127 & $60(-10$ to 130$)$ \\
\hline -Wt loss, group & 51 & $-21(-164$ to 123$)$ & 51 & $66(-27$ to 158$)$ \\
\hline -Wt loss, combination & 75 & $-2(-81$ to 77$)$ & 75 & $93(45 \text { to } 141)^{* * *}$ \\
\hline
\end{tabular}


Table 4 Change in dietary and physical activity outcomes at 12 months $^{\mathrm{a}}$ (Continued)

\begin{tabular}{|c|c|c|c|c|}
\hline \multicolumn{5}{|l|}{ Activity time, $\min / w^{f}$} \\
\hline All & 221 & -26 (-96 to 44$)$ & 253 & $83(30 \text { to } 136)^{* *}$ \\
\hline -African American & 153 & $-19(-115$ to 77$)$ & 178 & $75(14 \text { to } 136)^{*}$ \\
\hline -White & 66 & $-42(-115$ to 32$)$ & 73 & $110(2 \text { to } 218)^{*}$ \\
\hline -Lifestyle & 95 & $3(-84$ to 90$)$ & 127 & 67 (-24 to 158$)$ \\
\hline -Wt loss, group & 51 & $-90(-310$ to 131$)$ & 51 & $108(9 \text { to } 208)^{*}$ \\
\hline -Wt loss, combination & 75 & $-19(-105$ to 66$)$ & 75 & $93(35 \text { to } 151)^{* *}$ \\
\hline
\end{tabular}

Abbreviations: $B P$ blood pressure, $C l$ confidence interval, DRA dietary risk assessment

Note: Boldface indicates statistical significance ${ }^{*} p \leq 0.05 ;{ }^{* *} p \leq 0.01 ;{ }^{* * *} p \leq 0.001$

a Data are means except where noted

b 3 categorized as other race

c Participants selected intervention group at 6 month follow-up visit; if they did not attend this visit they were assigned to lifestyle group

d Carotenoid index, calculated as the sum of a-carotene, $\beta$-carotene, $\beta$-cryptoxanthin, and zeaxanthin. Data presented are for nonsmokers and available only

through 12 month follow-up visit. A higher index indicates greater fruit and vegetable consumption. Statistical tests performed on log-transformed data

e Includes walking for transportation and exercise

${ }^{f}$ Includes walking and other moderate and vigorous activity

was: systolic, $-9.3 \mathrm{mmHg}(-13.6$ to -5.1$)$; diastolic $-7.0 \mathrm{mmHg}(-9.0$ to -4.9$)$. At 12 months, among all participants there was a significant change in HDL-C of $-2 \mathrm{mg} / \mathrm{dL}(-2.8$ to -0.4$)$ and a non-significant change in total cholesterol of $-3 \mathrm{mg} / \mathrm{dL}$ ( -7.0 to 0.7 ).

From baseline to 12 months, weight change was $-0.9 \mathrm{~kg}$ ( -2.1 to 0.2$)$ for the lifestyle maintenance intervention, with 24 (19\%) losing $\geq 5 \%$ body weight; $-3.1 \mathrm{~kg}$ (-4.9 to -1.3) for the group-based weight loss intervention, with 17 (34 \%) losing $\geq 5 \%$ body weight; and $-2.1 \mathrm{~kg}$ (-3.2 to $-1.0)$ for the combination weight loss intervention, with $17(23 \%) \geq 5 \%$ body weight. During Phase II, outcomes were similar for African Americans and Whites. At the completion of Phase II, 46 participants in the group-based and 70 in the combination weight loss intervention completed an acceptability survey. Among group participants, $37(80 \%)$ reported they were very satisfied and 6 (13\%) reported they were satisfied with the intervention. For combination participants, 51 (71\%) reported they were very satisfied and $12(17 \%)$ reported they were satisfied with the intervention.

\section{Phase III outcomes}

Of the 30 participants who lost $\geq 8 \mathrm{lb}$ at 12 month follow-up, 27 (90\%) agreed to take part in the maintenance of weight loss RCT, while 258 received the lifestyle maintenance intervention (Fig. 3). Among those in the $\mathrm{RCT}$, compared to baseline, weight change was $-7.0 \mathrm{~kg}$ at 12 and $-5.9 \mathrm{~kg}$ at 24 months for the 15 participants in the intensive intervention and $-6.9 \mathrm{~kg}$ and $-2.4 \mathrm{~kg}$, respectively for the 12 participants in the less intensive intervention. Those losing $\geq 5 \%$ body weight at 24 months included 7 (47\%) receiving the more intensive and 3 (25\%) receiving the less intensive intervention.
Change in outcomes from 12 to 24 and baseline to 24 months for all returnees are shown in Tables 6 and 7 . In general, during the 2nd year of the intervention, there was minor attenuation in self-reported dietary behaviors and more pronounced attenuation of PA. Change in BP from baseline to 24 months among participants in the lifestyle only study was: systolic, -4.2 ( -7.3 to 1.2$)$; diastolic $-5.2(-7.1$ to -3.3$)$. For those in both studies, it was: systolic, -9.4 (-13.4 to -5.4$)$; diastolic $-7.8(-10.1$ to $-5.5)$. Compared to baseline, weight change was $-1.7 \mathrm{~kg}$ $(-2.9$ to -0.5$)$ for the lifestyle only intervention with 29 (23 \%) losing $\geq 5 \%$ body weight, $-2.1 \mathrm{~kg}$ (-4.3 to 0.0$)$ for the group weight loss intervention with 13 (25\%) losing $\geq$ $5 \%$ body weight, and $-1.1 \mathrm{~kg}(-2.7$ to 0.4$)$ for the combination weight loss intervention with $15(21 \%) \geq 5 \%$ body weight. During Phase III, outcomes were similar for African Americans and Whites. Change in blood lipids at 24 month was minimal.

\section{Predictors of BP change, quality of life, and adverse events}

At all follow-up time points, we examined the association between change in $\mathrm{BP}$ as a function of change in diet, PA, or weight, controlling for the baseline value of $\mathrm{BP}$ and baseline assessment of age, sex, race, educational achievement, diabetes status, and weight. In our model for change in diastolic BP at 24 month follow-up, weight loss was significantly associated with a reduction in diastolic BP $(p=0.03)$ for all participants and for those in both studies $(p=0.02)$. There were no other significant associations. At 6 and 12 month follow-up, quality of life measures were generally improved, but not significantly. At 24 month follow-up, compared to baseline there was statistically significant improvement in the mental 
Table 5 Change in blood pressure medication and physiologic outcomes at 12 months ${ }^{a}$

\begin{tabular}{|c|c|c|c|c|}
\hline \multirow[t]{4}{*}{ Outcome } & \multicolumn{4}{|c|}{ Phase 2} \\
\hline & \multicolumn{2}{|c|}{6 months to 12 months } & \multicolumn{2}{|c|}{ Baseline to 12 months } \\
\hline & \multicolumn{2}{|c|}{ (12 months minus 6 months) } & \multicolumn{2}{|c|}{ (12 months minus baseline) } \\
\hline & $\mathrm{n}$ & Mean, $95 \% \mathrm{Cl}$ & $\mathrm{n}$ & Mean, $95 \% \mathrm{Cl}$ \\
\hline \multicolumn{5}{|l|}{ Blood Pressure Medication } \\
\hline \multicolumn{5}{|c|}{ Taking BP lowering medication, \% } \\
\hline All & 221 & $-0.5 \%(-2.8$ to 1.9$)$ & 253 & $0.0 \%(-3.3$ to 3.3$)$ \\
\hline -African American & 153 & $0.0 \%(-3.1$ to 3.1$)$ & 178 & $-0.6 \%(-4.5$ to 3.4$)$ \\
\hline -White & 66 & $-1.5 \%(-4.5$ to 1.4$)$ & 73 & $1.4 \%(-4.6$ to 7.4$)$ \\
\hline -Lifestyle & 95 & $-1.0 \%(-3.1$ to 1.0$)$ & 127 & $-0.8 \%(-5.4$ to 3.8$)$ \\
\hline$-W t$ loss, group & 51 & $-2.0 \%$ ( -8.6 to 4.7$)$ & 51 & $-2.0 \%(-10.5$ to 6.6$)$ \\
\hline -Wt loss, combination & 75 & $1.3 \%(-3.2$ to 5.8$)$ & 75 & $2.7 \%(-2.5$ to 7.9$)$ \\
\hline \multicolumn{5}{|l|}{ Physiologic } \\
\hline \multicolumn{5}{|l|}{ Systolic BP, mm Hg } \\
\hline LS study only & 99 & $3.2(0.3 \text { to } 6.2)^{*}$ & 101 & $-1.4(-4.5$ to 1.6$)$ \\
\hline LS and HBP study & 121 & $-2.5(-6.5$ to 1.4$)$ & 150 & $-9.3(-13.6 \text { to }-5.1)^{* * *}$ \\
\hline All & 220 & $0.0(-2.5$ to 2.6$)$ & 251 & $-6.1(-9.0 \text { to }-3.3)^{* * *}$ \\
\hline \multicolumn{5}{|l|}{ Subgroup by race ${ }^{b}$} \\
\hline -African American & 152 & $-0.9(-4.0$ to 2.1$)$ & 176 & $-6.9(-10.5 \text { to }-3.3)^{* * *}$ \\
\hline -White & 66 & $2.5(-2.5$ to 7.4$)$ & 73 & $-4.2(-8.8$ to 0.3$)$ \\
\hline \multicolumn{5}{|l|}{ Subgroup by intervention ${ }^{c}$} \\
\hline -Lifestyle & 95 & $-2.2(-6.2$ to 1.8$)$ & 126 & $-8.3(-12.6 \text { to }-3.9)^{* * *}$ \\
\hline -Wt loss, group & 50 & $3.3(-1.0$ to 7.6$)$ & 50 & $-3.6(-7.8$ to 0.5$)$ \\
\hline -Wt loss, combination & 75 & $0.7(-3.8$ to 5.3$)$ & 75 & $-4.3(-9.7$ to 1.1$)$ \\
\hline \multicolumn{5}{|l|}{ Diastolic BP, mm Hg } \\
\hline LS study only & 99 & $0.4(-1.4$ to 2.2$)$ & 101 & $-2.0(-3.7 \text { to }-0.4)^{*}$ \\
\hline LS and HBP study & 121 & $-3.1(-5.3 \text { to }-1.0)^{* *}$ & 150 & $-7.0(-9.0 \text { to }-4.9)^{* * *}$ \\
\hline All & 220 & $-1.5(-2.9 \text { to }-0.1)^{*}$ & 251 & $-5.0(-6.4 \text { to }-3.6)^{* * *}$ \\
\hline -African American & 152 & $-2.3(-4.0 \text { to }-0.5)^{* *}$ & 176 & $-5.2(-7.0 \text { to }-3.4)^{* * *}$ \\
\hline -White & 66 & $0.7(-1.8$ to 3.2$)$ & 73 & $-4.2(-6.4 \text { to }-1.9)^{* * *}$ \\
\hline -Lifestyle & 95 & $-2.2(-4.4$ to 0.1$)$ & 126 & $-5.4(-7.5 \text { to }-3.2)^{* * * *}$ \\
\hline -Wt loss, group & 50 & $1.2(-1.0$ to 3.4$)$ & 50 & $-4.2(-6.9 \text { to }-1.6)^{* *}$ \\
\hline -Wt loss, combination & 75 & $-2.5(-5.1$ to 0.1$)$ & 75 & $-4.5(-7.2 \text { to }-2.3)^{* * *}$ \\
\hline \multicolumn{5}{|l|}{ Weight, kg } \\
\hline All & 219 & $-1.1(-1.7 \text { to }-0.5)^{* * *}$ & 250 & $-1.7(-2.5 \text { to } 1.0)^{* * *}$ \\
\hline -African American & 151 & $-0.9(-1.6 \text { to }-0.3)^{* *}$ & 175 & $-1.7(-2.6 \text { to }-0.8)^{* * *}$ \\
\hline -White & 66 & $-1.4(-2.3 \text { to }-0.3)^{*}$ & 73 & $-1.6(-3.1 \text { to }-0.2)^{*}$ \\
\hline -Lifestyle & 94 & $-0.3(-1.3$ to 0.6$)$ & 125 & $-0.9(-2.1$ to 0.2$)$ \\
\hline -Wt loss, group & 50 & $-1.3(-2.4 \text { to }-0.2)^{*}$ & 50 & $-3.1(-4.9 \text { to }-1.3)^{* * *}$ \\
\hline -Wt loss, combination & 75 & $-1.9(-2.8 \text { to }-1.0)^{* * *}$ & 75 & $-2.1(-3.2 \text { to }-1.0)^{* * *}$ \\
\hline \multicolumn{5}{|l|}{ Weight, $\geq 5 \%$ weight loss, $\%$} \\
\hline All & 219 & $18 \%$ (13 to 23$)$ & 250 & $23 \%$ (18 to 28$)$ \\
\hline -African American & 151 & $18 \%$ (12 to 24$)$ & 175 & $23 \%$ (17 to 30$)$ \\
\hline -White & 66 & $18 \%$ (9 to 28$)$ & 73 & $22 \%(12$ to 31$)$ \\
\hline -Lifestyle & 94 & $14 \%$ (7 to 21$)$ & 125 & $19 \%$ (12 to 26$)$ \\
\hline
\end{tabular}


Table 5 Change in blood pressure medication and physiologic outcomes at 12 months ${ }^{\mathrm{a}}$ (Continued)

\begin{tabular}{|c|c|c|c|c|}
\hline -Wt loss, group & 50 & $22 \%$ (10 to 34 & 50 & $34 \%$ (21 to 47$)$ \\
\hline -Wt loss, combination & 75 & $21 \%(12$ to 31$)$ & 75 & $23 \%$ (13 to 32$)$ \\
\hline \multicolumn{5}{|l|}{ Total cholesterol, mg/dL } \\
\hline All & & & 221 & $-3(-7.0$ to 0.7$)$ \\
\hline -African American & & & 155 & $-4(-8.5$ to 0.4$)$ \\
\hline -White & & & 64 & 0 (-7.8 to 7.7$)$ \\
\hline -Lifestyle & & & 106 & $-3(-9.1$ to 2.7$)$ \\
\hline$-W t$ loss, group & & & 44 & $-6(-13.5$ to 1.4$)$ \\
\hline -Wt loss, combination & & & 71 & -1 ( -8.0 to 5.2$)$ \\
\hline \multicolumn{5}{|l|}{ HDL cholesterol, mg/dL } \\
\hline All & & & 220 & $-2(-2.8 \text { to }-0.4)^{* *}$ \\
\hline -African American & & & 154 & $-2(-3.0 \text { to } 0)^{*}$ \\
\hline -White & & & 64 & $-2(-3.8$ to 0.3$)$ \\
\hline -Lifestyle & & & 106 & $-2(-3.8$ to -0.1$)$ \\
\hline -Wt loss, group & & & 44 & $-1(-3.1$ to 1.5$)$ \\
\hline -Wt loss, combination & & & 70 & $-1(-3.5$ to 0.5$)$ \\
\hline
\end{tabular}

Abbreviations: $B P$ blood pressure, $C l$ confidence interval, $H B P$ high blood pressure, $L S$ lifestyle

Note: Boldface indicates statistical significance ${ }^{*} p \leq 0.05 ;{ }^{* *} p \leq 0.01 ;{ }^{* * *} p \leq 0.001$.

SI unit conversion factors: To convert all types of cholesterol to millimoles per liter, multiply by 0.0259

${ }^{a}$ Data are means except where noted

b 3 categorized as other race

' Participants selected intervention group at 6 month follow-up visit; if they did not attend this visit they were assigned to lifestyle group

${ }^{\mathrm{d}}$ To convert from $\mathrm{mg} / \mathrm{dL}$ to $\mathrm{mmol} / \mathrm{L}$ divide by 68.37

composite score for all participants and for the lifestyle subgroup $(p<.05)$. There were no adverse events attributed to the intervention; however, 23 participants had at least one adverse CVD event during follow-up, including: 3 acute myocardial infarctions ( 1 death), 5 hospital evaluations for angina, 1 coronary artery bypass surgery, 6 episodes of heart failure, 3 hospital evaluations for hypertension, 2 strokes, and 3 others.

\section{Discussion}

In this study to evaluate a diet, PA, and weight loss intervention that promoted a Mediterranean style eating pattern adapted for the southeastern US, participants reported substantial improvements in dietary behaviors (improved consumption of high quality fats and fruit and vegetables) at 6 month follow-up that were generally maintained through 24 months, with increases in selfreported fruit and vegetable consumption corroborated by the objective measure of blood carotenoids at 12 month follow-up. A major difference between the diet pattern tested in this study and most previous dietary intervention trials conducted in the US, including several we have conducted in low-income populations [39, 45-48, 67, 68] was the recommendation to increase consumption of foods containing high quality fats (no restriction on total fat intake), with a focus on increasing fat intake from nuts and vegetable oils. We believe this recommendation to consume more healthful fats was well received because we encouraged consumption of many foods that historically have been an important part of the southern diet, but previously discouraged by dietary guidelines focusing on fat restriction. Perhaps this appealing aspect of the Med-South Diet contributed to the maintenance of dietary change through 24 months.

A major goal of this project was to develop an intervention that would be similarly effective among minority and non-minority participants, in hopes that such an intervention may decrease health disparities. Overall, both lifestyle and physiologic outcomes were similar by race. Moreover, for systolic $\mathrm{BP}$, there were trends towards a greater reduction among African American participants.

Relevant to our findings on BP change, in a sub-study of the PREDIMED randomized trial, Estruch [22] examined the effect on BP of a Mediterranean diet supplemented with extra virgin olive oil $(n=257)$ and nuts $(n=257)$ compared to a low-fat diet $(n=256)$. At 3 month follow-up, systolic BP was reduced by $4.8 \mathrm{mmHg}$ in the olive oil group and $6.5 \mathrm{mmHg}$ in the nuts group, with $0.64 \mathrm{mmHg}$ increase in the lowfat group. In our study, among participants in the lifestyle only group, we observed a similar reduction 
Table 6 Change in dietary and physical activity outcomes at 24 months ${ }^{a}$

\begin{tabular}{|c|c|c|c|c|}
\hline \multirow[t]{4}{*}{ Outcome } & \multicolumn{4}{|c|}{ Phase 3} \\
\hline & \multicolumn{2}{|c|}{12 months to 24 months } & \multicolumn{2}{|c|}{ Baseline to 24 months } \\
\hline & \multicolumn{2}{|c|}{ (24 months minus 12 months) } & \multicolumn{2}{|c|}{ (24 months minus baseline) } \\
\hline & $\mathrm{n}$ & Mean, 95 \% Cl & $n$ & Mean, $95 \% \mathrm{Cl}$ \\
\hline \multicolumn{5}{|l|}{ Dietary } \\
\hline \multicolumn{5}{|l|}{ DRA total score } \\
\hline All & 236 & $-0.3(-0.8$ to 0.2$)$ & 226 & $2.9(2.3 \text { to } 3.6)^{* * *}$ \\
\hline \multicolumn{5}{|l|}{ Subgroup by race ${ }^{b}$} \\
\hline -African American & 168 & $-0.7(-1.3 \text { to } 0.0)^{*}$ & 158 & $3.0(2.2 \text { to } 3.8)^{* * *}$ \\
\hline -White & 66 & $0.6(-0.2$ to 1.4$)$ & 66 & $2.8(1.6 \text { to } 4.0)^{* * *}$ \\
\hline \multicolumn{5}{|l|}{ Subgroup by intervention ${ }^{c}$} \\
\hline -Lifestyle & 116 & $-0.1(-0.8$ to 0.6$)$ & 105 & $1.8(0.9 \text { to } 2.7)^{* * *}$ \\
\hline$-W t$ loss, group & 48 & $-1.1(-2.1 \text { to }-0.2)^{*}$ & 50 & $4.0(2.7 \text { to } 5.4)^{* * *}$ \\
\hline -Wt loss, combination & 72 & $0.0(-0.9$ to 1.0$)$ & 71 & $3.9(2.6 \text { to } 5.2)^{* * *}$ \\
\hline \multicolumn{5}{|l|}{ Fat quality screener score } \\
\hline All & 236 & $-0.4(-0.7 \text { to } 0)^{*}$ & 224 & $0.7(0.3 \text { to } 1.0)^{* * *}$ \\
\hline -African American & 168 & $-0.6(-1.0 \text { to }-0.1)^{* *}$ & 156 & $0.7(0.2 \text { to } 1.1)^{* *}$ \\
\hline -White & 66 & $0.1(-0.5$ to 0.6$)$ & 66 & $0.6(-0.2$ to 1.5$)$ \\
\hline -Lifestyle & 116 & $-0.7(-1.3 \text { to }-0.2)^{* *}$ & 105 & $0.1(-0.5$ to 0.7$)$ \\
\hline -Wt loss, group & 48 & $-0.2(-0.9$ to 0.5$)$ & 47 & $1.2(0.4 \text { to } 2.0)^{* *}$ \\
\hline -Wt loss, combination & 72 & $0.1(-0.5$ to 0.6$)$ & 72 & $1.1(0.5 \text { to } 1.7)^{* * *}$ \\
\hline \multicolumn{5}{|c|}{ Fruit and vegetable servings per day } \\
\hline All & 237 & $-0.2(-0.4$ to 0.1$)$ & 250 & $0.4(0.2 \text { to } 0.6)^{* * *}$ \\
\hline -African American & 169 & $-0.2(-0.5$ to 0.1$)$ & 177 & $0.3(0.1 \text { to } 0.6)^{*}$ \\
\hline -White & 66 & $0.0(-0.4$ to 0.3$)$ & 71 & $0.5(0.1 \text { to } 0.8)^{* *}$ \\
\hline -Lifestyle & 117 & $0.1(-0.2$ to 0.4$)$ & 127 & $0.2(-0.1$ to 0.5$)$ \\
\hline -Wt loss, group & 48 & $-0.1(-0.6$ to 0.3$)$ & 51 & $0.9(0.4 \text { to } 1.4)^{* * *}$ \\
\hline -Wt loss, combination & 72 & $-0.5(-0.9 \text { to }-0.1)^{* *}$ & 72 & $0.3(-0.1$ to 0.8$)$ \\
\hline \multicolumn{5}{|l|}{ Physical Activity } \\
\hline \multicolumn{5}{|l|}{ Walking time, $\mathrm{min} / \mathrm{wk}^{\mathrm{d}}$} \\
\hline All & 237 & $-52(-89 \text { to }-15)^{* *}$ & 250 & $22(-13$ to 56$)$ \\
\hline -African American & 169 & $-49(-95 \text { to }-3)^{*}$ & 177 & $21(-25$ to 67$)$ \\
\hline -White & 66 & $-63(-123 \text { to }-2)^{*}$ & 71 & $27(-12$ to 65$)$ \\
\hline -Lifestyle & 117 & $-55(-111$ to 2$)$ & 127 & $8(-50$ to 65$)$ \\
\hline -Wt loss, group & 48 & $-81(-163 \text { to } 0)^{*}$ & 51 & -4 ( -69 to 60$)$ \\
\hline -Wt loss, combination & 72 & -29 ( -84 to 27$)$ & 72 & $65(22 \text { to } 108)^{* *}$ \\
\hline
\end{tabular}


Table 6 Change in dietary and physical activity outcomes at 24 months $^{\mathrm{a}}$ (Continued)

\begin{tabular}{|c|c|c|c|c|}
\hline \multicolumn{5}{|l|}{ Activity time, $\mathrm{min} / \mathrm{wk}^{\mathrm{e}}$} \\
\hline All & 237 & $-40(-91$ to 11$)$ & 250 & $48(-7$ to 103$)$ \\
\hline -African American & 169 & -25 (-89 to 40$)$ & 177 & $54(-17$ to 124$)$ \\
\hline -White & 66 & $-82(-164 \text { to }-0.5)^{*}$ & 71 & $39(-46$ to 124$)$ \\
\hline -Lifestyle & 117 & $-17(-106$ to 73$)$ & 127 & $51(-46$ to 149$)$ \\
\hline -Wt loss, group & 48 & $-116(-208 \text { to }-24)^{* *}$ & 51 & $12(-70$ to 95$)$ \\
\hline -Wt loss, combination & 72 & $-27(-84$ to 29$)$ & 72 & $68(7 \text { to } 129)^{*}$ \\
\hline
\end{tabular}

Abbreviations: $B P$ blood pressure, $C l$ confidence interval, $D R A$ dietary risk assessment

Note: Boldface indicates statistical significance ${ }^{*} p \leq 0.05 ;{ }^{* *} p \leq 0.01 ;{ }^{* * *} p \leq 0.001$

a Data are means except where noted

b 3 categorized as other race

c Participants selected intervention group at 6 month follow-up visit; if they did not attend this visit they were assigned to lifestyle group

d Includes walking for transportation and exercise

e Includes walking and other moderate and vigorous activity

in systolic BP at 6 and 24 month follow-up, with a smaller reduction at 12 months. Among those taking part in both the lifestyle and high BP studies, the reduction in systolic BP was larger at all follow-up time up, likely due to the combined effect of diet and PA change and improved medication adherence. With regard to blood lipid change, in the PREDIMED substudy, total cholesterol was reduced by $3.9 \mathrm{mg} / \mathrm{dL}$ in the olive oil group and $5.0 \mathrm{mg} / \mathrm{dL}$ in the nuts group, while increasing $0.74 \mathrm{mg} / \mathrm{dL}$ in the low-fat group. In our study, total cholesterol was reduced $3 \mathrm{mg} / \mathrm{dL}$ at 12 and 24 month follow-up. However, in the PREDIMED study, HDL-C increased 2.4 and $0.9 \mathrm{mg} / \mathrm{dL}$ in the olive oil and nut groups respectively, while decreasing $0.4 \mathrm{mg} / \mathrm{dL}$ in the low-fat group. Despite improved selfreported diet and PA behaviors and modest weight loss, in our study, HDL-C was reduced by 2 and $1 \mathrm{mg} / \mathrm{dL}$, respectively at 12 and 24 month follow-up.

Of the 249 participants taking part in Phase II that returned for 6 month follow-up weights, 231 (93 \%) had a BMI $>25 \mathrm{~kg} / \mathrm{m}^{2}$ and were eligible for the weight loss intervention. It is noteworthy that 138 (60\%) elected to receive the weight loss intervention, suggesting a high level of interest in weight loss among overweight study participants. Though a sub-set of weight loss participants achieved and maintained meaningful weight loss; overall, the weight loss component of this trial did not achieve study goals. First, we expected $60 \%$ of participants to take part in the weight loss program, but only 138 (40\% of enrollees and $55 \%$ of those returning and eligible at 6 month follow-up) elected to do so. Second, for weight loss participants, the average weight loss at the conclusion of the weight loss intervention (baseline to 12 months) of $2.5 \mathrm{~kg}$ was less than observed in our previous weight loss intervention trials [40, 41]. Because fewer participants elected to take part in the weight loss intervention and weight loss was less than expected, the embedded RCT of weight loss maintenance was substantially underpowered. Possible reasons for less weight loss than expected include the non-selected sample (in our prior weight loss studies, participants were screened for motivation to lose weight) and an older population with more co-morbidities. An unexpected positive finding was that $20 \%$ of African American participants who returned for follow-up at the conclusion of Phase I, which was not a weight loss intervention, lost $\geq 5 \%$ of body weight.

Though the US Preventive Services Task Force [69] recommends clinicians should offer and refer all adults with $\mathrm{BMI} \geq 30 \mathrm{~kg} / \mathrm{m}^{2}$ to an intensive weight loss program, most published weight loss studies conducted in primary care and community settings [70-72] have included selected samples, often younger, with lower BMI, and with less co-morbidities than those seen in routine practice. In contrast, we offered our weight loss intervention to a non-selected, high risk, older, and largely minority sample. With the caveat that our weight change was compared to baseline and not a control group, our achieved weight loss, though modest, was greater than reported in a recent meta-analysis by Booth [70] assessing behavioral weight loss programs in primary care settings with pooled results across 15 RCTs of $-1.4 \mathrm{~kg}(-2.1$ to -0.6$)$. Furthermore, in a recent review [31] of weight loss studies conducted in disadvantaged populations, only $20 \%$ lost more than $5 \%$ of body weight at follow-up, which is less than we achieved in this study. However, overall weight loss was modest, especially at 24 month follow-up, highlighting the need for more effective weight loss interventions for high risk populations, as enrolled in this study.

This study has several limitations. The overall design (excluding the embedded RCT) was a pre-post comparison study with no control group. Thus, observed 
Table 7 Change in blood pressure medication and physiologic outcomes at 24 months ${ }^{a}$

\begin{tabular}{|c|c|c|c|c|}
\hline \multirow[t]{4}{*}{ Outcome } & \multicolumn{4}{|c|}{ Phase 3} \\
\hline & \multicolumn{2}{|c|}{12 months to 24 months } & \multicolumn{2}{|c|}{ Baseline to 24 months } \\
\hline & \multicolumn{2}{|c|}{ (24 months minus 12 months) } & \multicolumn{2}{|c|}{ (24 months minus baseline) } \\
\hline & $\mathrm{n}$ & Mean, $95 \% \mathrm{Cl}$ & $\mathrm{n}$ & Mean, $95 \% \mathrm{Cl}$ \\
\hline \multicolumn{5}{|l|}{ Blood Pressure Medication } \\
\hline \multicolumn{5}{|c|}{ Taking BP lowering medication, \% } \\
\hline All & 237 & $0.4 \%(-2.3$ to 3.2$)$ & 250 & $0.8 \%(-3.0$ to 4.6$)$ \\
\hline -African American & 169 & $1.2 \%(-1.6$ to 4.0$)$ & 177 & $1.1 \%(-3.3$ to 5.6$)$ \\
\hline -White & 66 & $0.0 \%(-5.9$ to 5.9$)$ & 71 & $1.4 \%(-5.9$ to 8.7$)$ \\
\hline -Lifestyle & 117 & $2.6 \%(-1.1$ to 6.3$)$ & 127 & $1.6 \%(-4.2$ to 7.3$)$ \\
\hline$-W t$ loss, group & 48 & $2.1 \%(-5.0$ to 9.1$)$ & 51 & $2.0 \%(-6.6$ to 10.5$)$ \\
\hline -Wt loss, combination & 72 & $-4.2 \%$ ( -8.8 to 0.4$)$ & 72 & $-1.4 \%(-7.5$ to 4.7$)$ \\
\hline \multicolumn{5}{|l|}{ Physiologic } \\
\hline \multicolumn{5}{|l|}{ Systolic BP, mm Hg } \\
\hline LS study only & 95 & $-2.8(-6.4$ to 0.7$)$ & 104 & $-4.2(-7.3 \text { to } 1.2)^{* *}$ \\
\hline LS and HBP study & 140 & $-0.2(-3.8$ to 3.5$)$ & 146 & $-9.4(-13.4 \text { to }-5.4)^{* * *}$ \\
\hline All & 235 & $-1.3(-3.9$ to 1.3$)$ & 250 & $-7.2(-9.9 \text { to }-4.6)^{* * *}$ \\
\hline \multicolumn{5}{|l|}{ Subgroup by race ${ }^{b}$} \\
\hline -African American & 167 & $-2.0(-5.3$ to 1.2$)$ & 177 & $-8.4(-11.8 \text { to }-5.1)^{* * * *}$ \\
\hline -White & 66 & $0.9(-3.3$ to 5.2$)$ & 71 & $-4.1(-8.5$ to 0.4$)$ \\
\hline \multicolumn{5}{|l|}{ Subgroup by intervention ${ }^{c}$} \\
\hline -Lifestyle & 116 & $-1.2(-4.9$ to 2.5$)$ & 127 & $-8.8(-12.9 \text { to }-4.8)^{* * *}$ \\
\hline -Wt loss, group & 47 & $0.4(-3.9$ to 4.8$)$ & 51 & $-3.9(-8.4$ to 0.6$)$ \\
\hline -Wt loss, combination & 72 & $-2.4(-7.8$ to 2.9$)$ & 72 & $-6.8(-11.8 \text { to }-1.9)^{* *}$ \\
\hline \multicolumn{5}{|l|}{ Diastolic BP, mm Hg } \\
\hline LS study only & 95 & $-3.4(-5.4 \text { to }-1.5)^{* * *}$ & 104 & $-5.2(-7.1 \text { to }-3.3)^{* * *}$ \\
\hline LS and HBP study & 140 & $-0.9(-2.9$ to 1.0$)$ & 146 & $-7.8(-10.1 \text { to }-5.5)^{* * *}$ \\
\hline All & 235 & $-1.9(-3.4$ to -0.5$)$ & 250 & $-6.7(-8.3 \text { to }-5.1)^{* * *}$ \\
\hline -African American & 167 & $-2.4(-4.2 \text { to } 0.5)^{* *}$ & 177 & $-7.2(-9.2 \text { to }-5.1)^{* * *}$ \\
\hline -White & 66 & $-1.0(-3.0$ to 1.0$)$ & 71 & $-5.4(-7.6 \text { to }-3.3)^{* * *}$ \\
\hline -Lifestyle & 116 & $-1.9(-4.0$ to 0.2$)$ & 127 & $-6.8(-9.1 \text { to }-4.4)^{* * * *}$ \\
\hline -Wt loss, group & 47 & $-3.1(-5.8 \text { to }-0.4)^{*}$ & 51 & $-7.7(-10.7 \text { to }-4.6)^{* * * *}$ \\
\hline -Wt loss, combination & 72 & $-1.3(-3.9$ to 1.3$)$ & 72 & $-6.0(-8.8 \text { to }-3.2)^{* * *}$ \\
\hline \multicolumn{5}{|l|}{ Weight, kg } \\
\hline All & 232 & 0.1 (-0.6 to 0.8$)$ & 247 & $-1.6(-2.5 \text { to }-0.7)^{* * *}$ \\
\hline -African American & 164 & $-0.1(-1.0$ to .08$)$ & 174 & $-1.8(-2.8 \text { to }-0.8)^{* * *}$ \\
\hline -White & 66 & $0.6(-0.6$ to 1.7$)$ & 71 & $-1.0(-2.9$ to 0.8$)$ \\
\hline -Lifestyle & 113 & $-0.9(-2.0$ to 0.1$)$ & 124 & $-1.7(-2.9 \text { to }-0.5)^{* *}$ \\
\hline -Wt loss, group & 47 & $1.2(-0.4$ to 2.8$)$ & 51 & $-2.1(-4.3 \text { to } 0.0)^{*}$ \\
\hline -Wt loss, combination & 72 & $1.0(-0.2$ to 2.2$)$ & 72 & $-1.1(-2.7$ to 0.4$)$ \\
\hline \multicolumn{5}{|l|}{ Weight, $\geq 5 \%$ weight loss, $\%$} \\
\hline All & 232 & $12 \%$ (8 to 16$)$ & 247 & $23 \%$ (18 to 28$)$ \\
\hline -African American & 164 & $12 \%$ (7 to 17$)$ & 174 & $24 \%$ (18 to 31$)$ \\
\hline -White & 66 & $12 \%$ (4 to 20 ) & 71 & $18 \%$ (9 to 27$)$ \\
\hline -Lifestyle & 113 & $16 \%$ (9 to 23$)$ & 124 & $23 \%$ (16 to 31$)$ \\
\hline
\end{tabular}


Table 7 Change in blood pressure medication and physiologic outcomes at 24 months ${ }^{\mathrm{a}}$ (Continued)

\begin{tabular}{|c|c|c|c|c|}
\hline -Wt loss, group & 47 & $11 \%(2$ to 20$)$ & 51 & $25 \%$ (13 to 38$)$ \\
\hline -Wt loss, combination & 72 & $7 \%$ (1 to 13$)$ & 72 & $21 \%$ (11 to 30$)$ \\
\hline \multicolumn{5}{|l|}{ Total cholesterol, mg/dL } \\
\hline All & 196 & $1(-3.3$ to 5.0$)$ & 211 & $-3(-7.8$ to 1.7$)$ \\
\hline -African American & 139 & $-1(-6.3$ to 4.7$)$ & 148 & $-4(-10.3$ to 1.4$)$ \\
\hline -White & 55 & $4(-0.9$ to 9.8$)$ & 61 & $1(-7.3$ to 9.2$)$ \\
\hline -Lifestyle & 91 & $2(-4.0$ to 8.8$)$ & 99 & $-2(-8.1$ to 4.3$)$ \\
\hline -Wt loss, group & 41 & $-3(-13.7$ to 7.2$)$ & 46 & $-9(-20.9$ to 3.7$)$ \\
\hline -Wt loss, combination & 64 & $1(-4.7$ to 7.1$)$ & 66 & $-1(-9.3$ to 7.2$)$ \\
\hline \multicolumn{5}{|l|}{ HDL cholesterol, mg/dL } \\
\hline All & 196 & $0(-0.8$ to 1.3$)$ & 211 & $-1(-2.3$ to 0.3$)$ \\
\hline -African American & 139 & $0(-1.2$ to 1.6$)$ & 148 & $-1(-2.6$ to 0.6$)$ \\
\hline -White & 55 & $0(-1.4$ to 2.2$)$ & 61 & $-1(-3.1$ to 1.2$)$ \\
\hline -Lifestyle & 91 & $0(-1.4$ to 1.7$)$ & 99 & $-2(-4.0 \text { to }-0.1)^{*}$ \\
\hline -Wt loss, group & 41 & 0 (-2.0 to 2.3$)$ & 46 & 1 (-1.6 to 3.6$)$ \\
\hline -Wt loss, combination & 64 & $0(-1.6$ to 2.4$)$ & 66 & $-1(-2.9$ to 1.4$)$ \\
\hline
\end{tabular}

Abbreviations: $B P$ blood pressure, $C l$ confidence interval, $H B P$ high blood pressure, $L S$ lifestyle

Note: Boldface indicates statistical significance ${ }^{*} p \leq 0.05 ;{ }^{* *} p \leq 0.01 ;{ }^{* * *} p \leq 0.001$

SI unit conversion factors: To convert all types of cholesterol to millimoles per liter, multiply by 0.0259

${ }^{a}$ Data are means except where noted

b 3 categorized as other race

' Participants selected intervention group at 6 month follow-up visit; if they did not attend this visit they were assigned to lifestyle group

${ }^{\mathrm{d}}$ To convert from $\mathrm{mg} / \mathrm{dL}$ to $\mathrm{mmol} / \mathrm{L}$ divide by 68.37

changes could be due to secular trends or other factors. With regard to secular trends, data on overweight and obesity from the behavioral risk factor surveillance system (BRFSS) for all of North Carolina and for Eastern North Carolina [73] suggest no reduction in weight for the adult population from 2011 to 2014 (see Additional file 2: Table S1). During this same time period, BRFSS data for both North Carolina and eastern North Carolina adults, suggest a slight increase in PA from 2011 to 2014 (see Additional file 3: Table S2). Many outcomes were self-reported, which may be exaggerated due to social desirability reporting bias. Also, we present many comparisons and some $p$-values may be significant by chance. Further, our sample size was relatively small for some of the subgroup outcomes reported. Finally, the generalizability of our findings may be limited to samples similar to those enrolled in this study.

\section{Conclusions}

In this study promoting a Mediterranean style dietary pattern as a major component of a lifestyle and weight loss intervention to reduce CVD risk, the large majority of participants reported substantial improvement in dietary intake and a meaningful percentage lost weight and maintained weight loss. Importantly, as lifestyle and physiologic changes were similar for African American and white participants, this type of culturally tailored intervention has the potential to reduce both CVD risk and disparities in CVD rates. Future research should include RCTs enrolling similar high risk populations that assess change in CVD risk factors and ultimately change in CVD events.

\section{Additional files}

Additional file 1: Description of and materials included in the intervention. (PDF $5292 \mathrm{~kb}$ )

Additional file 2: BRFSS Survey Results for Overweight and Obesity: Eastern North Carolina and North Carolina. (DOCX 14 kb)

Additional file 3: BRFSS Survey Results for Exercise: Eastern North Carolina and North Carolina. (DOCX 15 kb)

\section{Abbreviations}

$\mathrm{BP}$, blood pressure; $\mathrm{BMI}$, body mass index; $\mathrm{CAC}$, community advisory committee; CVD, cardiovascular disease; $\mathrm{dL}$, deciliter; DRA, dietary risk assessment; $\mathrm{HDL}-\mathrm{C}$, high density lipoprotein cholesterol; $\mathrm{HHL}$, heart healthy lenoir; kg, kilogram; PA, physical activity; PREDIMED, prevención con dieta mediterránea; $\mathrm{RCT}$, randomized controlled trial; SES, socioeconomic status; US, United States

\section{Acknowledgments}

We give special thanks to our Community Advisory Committee who provided helpful guidance with this project and to our study participants, whose willing participation made this study possible.

\section{Funding}

Funder: This research was supported by National Institutes of Health $(\mathrm{NIH})$ grant 5P50 HL105184 to the University of North Carolina Center for Health Promotion and Disease Prevention (HPDP) with subcontract to the Brody School of Medicine, East Carolina University. Other support was provided by 
Centers for Disease Control and Prevention (CDC) cooperative agreement No. U48/DP001944 to HPDP (a CDC Prevention Research Center). Role of the Funder/Sponsor: The funding agencies had no role in the design and conduct of the study; collection, management, analysis, and interpretation of the data; and preparation, review, or approval of the manuscript; and decision to submit the manuscript for publication.

\section{Authors' contributions}

Drs. K and $\mathrm{G}$ had full access to all the data in the study and take responsibility for the integrity of the data and the accuracy of the data analysis. Study concept and design: K, SH, JP, G, E, A, D, H, Acquisition, analysis, or interpretation of data: All authors. Drafting of the manuscript: $K_{\text {, J }}$. Critical revision of the manuscript for important intellectual content: All authors. Statistical analysis: G, J. Administrative, technical, or material support: G, J, M. Study supervision: K, SH, G, A, D, H. All authors read and approved the final manuscript.

\section{Competing interests}

The authors declare that they have no competing interests.

\section{Consent for publication}

Not applicable.

\section{Ethics approval and consent to participate}

This study was initially approved by University of North Carolina at Chapel Hill's Institutional Review Board on February 25, 2010 with the annual renewal approved on Octorber 15, 2015. All study participants gave verbal consent for administraton of the study screening questionnaire (to assesse eligibility) and written consent before study data were collected.

\section{Availability of data and materials section}

The datasets generated during and/or analysed during the current study are being prepared for web access on the BioLINCC repository, available at: https://biolincc.nhlbi.nih.gov/home/

Until available on this repository, the data are available from the corresponding author on reasonable request.

\section{Author details}

'Division of General Medicine and Clinical Epidemiology, Department of Medicine, School of Medicine, CB 7110, University of North Carolina, 5039 Old Clinic Building, Chapel Hill, NC 27599, USA. ${ }^{2}$ Center for Health Promotion and Disease Prevention (a CDC Prevention Research Center), CB 7426, University of North Carolina, Chapel Hill, NC 27599, USA. ${ }^{3}$ Department of Public Health, Brody School of Medicine, East Carolina University, Lakeside Annex 8, 600 Moye Blvd, MS 660, Greenville, NC 27834, USA. ${ }^{4}$ Department of Nutrition, Gillings School of Global Public Health, CB 7461, University of North Carolina, Chapel Hill, NC 27599, USA. ${ }^{5}$ Department of Epidemiology, Gillings School of Global Public Health, CB 8050, University of North Carolina, Chapel Hill, NC 27599, USA. ${ }^{6}$ Greene County Health Department, 225 Kingold Blvd, Suite B, Snow Hill, North Carolina 28580, USA. ${ }^{7}$ Student Health Services, East Carolina University, 1000 East 5th St, MS 408, Greenville, NC 27858, USA. ${ }^{8}$ Department of Laboratory Medicine and Pathology, University of Minnesota, Minneapolis, MN 55455, USA. 'Department of Family Medicine, School of Medicine, CB 7595, University of North Carolina, Chapel Hill, NC 27599, USA. ${ }^{10} \mathrm{Cecil}$ G. Sheps Center for Health Services Research, School of Medicine, CB 7590, University of North Carolina, Chapel Hill, NC 27599, USA.

Received: 10 February 2016 Accepted: 23 July 2016

Published online: 05 August 2016

\section{References}

1. Bibbins-Domingo K, Pletcher M, Lin F, Vittinghoff E, Gardin J, Arynchyn A, et al. Racial differences in incident heart failure among young adults. N Engl J Med. 2009;360(12):1179-90. http://dx.doi.org/10.1056/Nejmoa0807265.

2. Bonow R, Grant A, Jacobs A. The cardiovascular state of the union: confronting healthcare disparities. Circulation. 2005;111(10):1205-7. http://dx.doi.org/10.1161/01.Cir.0000160705.97642.92.

3. Go A, Mozaffarian D, Roger V, Benjamin E, Berry J, Blaha M, et al. Executive summary: heart disease and stroke statistics-2014 update: a report from the American heart association. Circulation. 2014;129(3):399-410. http://dx.doi.org/10.1161/01.Cir.0000442015.53336.12.
4. Howard G, Labarthe D, Hu J, Yoon S, Howard V. Regional differences in African Americans' high risk for stroke: the remarkable burden of stroke for southern African Americans. Ann Epidemiol. 2007;17(9):689-96. http://dx.doi.org/10.1016/J.Annepidem.2007.03.019.

5. Mcwilliams J, Meara E, Zaslavsky A, Ayanian J. Differences in control of cardiovascular disease and diabetes by race, ethnicity, and education: U.S. Trends from 1999 to 2006 and effects of medicare coverage. Ann Intern Med. 2009; 150(8):505-15. http///dx.doi.org/10.7326/0003-4819-150-8-200904210-00005.

6. Peterson E, Yancy C. Eliminating racial and ethnic disparities in cardiac care. N Engl J Med. 2009;360(12):1172-4. http://dx.doi.org/10.1056/Nejmp0810121.

7. Smedley B, Stith A, Nelson A. Unequal treatment: confronting racial and ethnic disparities in health care. Washington, Dc: National Academies Press; 2003.

8. Williams $D$, Wyatt R. Racial bias in health care and health: challenges and opportunities. Jama. 2015;314(6):555-6. http://dx.doi.org/10.1001/Jama.2015.9260.

9. Centers For Disease Control And Prevention. Fruit and vegetable consumption among adults-United States, 2005. Mmwr Morb Mortal Wkly Rep. 2007;56(10):213-7.

10. Blanck H, Gillespie C, Kimmons J, Seymour J, Serdula M. Trends in fruit and vegetable consumption among U.S. Men and women, 1994-2005. Prev Chronic Dis. 2008:5(2):A35.

11. Krebs-Smith S, Cook A, Subar A, Cleveland L, Friday J. Us Adults' fruit and vegetable intakes, 1989 to 1991: a revised baseline for the healthy people 2000 objective. Am J Public Health. 1995;85(12):1623-9.

12. Serdula M, Gillespie C, Kettel-Khan L, Farris R, Seymour J, Denny C. Trends in fruit and vegetable consumption among adults in the united states: behavioral risk factor surveillance system, 1994-2000. Am J Public Health. 2004;94(6):1014-8.

13. Centers For Disease Control And Prevention. Prevalence of self-reported physically active adults-United States, 2007. Mmwr Morb Mortal Wkly Rep. 2008:57(48):1297-300.

14. Haskell W, Lee I, Pate R, Powell K, Blair S, Franklin B, et al. Physical activity and public health: updated recommendation for adults from the American College of sports medicine and the American heart association. Circulation. 2007;116(9):1081-93. http://dx.doi.org/10.1161/Circulationaha.107.185649.

15. Flegal K, Carroll M, Ogden C, Curtin L. Prevalence and trends in obesity among Us adults, 1999-2008. Jama. 2010;303(3):235-41. http://dx.doi.org/10.1001/Jama.2009.2014.

16. Mozaffarian D, Appel L, Van Horn L. Components of a cardioprotective diet: New insights. Circulation. 2011;123(24):2870-91. http://dx.doi.org/10.1161/Circulationaha.110.968735.

17. Zheng H, Orsini N, Amin J, Wolk A, Nguyen V, Ehrlich F. Quantifying the doseresponse of walking in reducing coronary heart disease risk: meta-analysis. Eur J Epidemiol. 2009;24(4):181-92. http://dx.doi.org/10.1007/S10654-009-9328-9.

18. Park Y, Subar A, Hollenbeck A, Schatzkin A. Dietary fiber intake and mortality in the Nih-aarp diet and health study. Arch Intern Med. 2011;171(12):1061-8 http://dx.doi.org/10.1001/Archinternmed.2011.18.

19. Wang $X$, Ouyang $Y$, Liu J, Zhu M, Zhao G, Bao W, et al. Fruit and vegetable consumption and mortality from All causes, cardiovascular disease, and cancer: systematic review and dose-response meta-analysis of prospective cohort studies. BMJ. 2014;349:G4490. http://dx.doi.org/10.1136/Bmj.G4490.

20. Estruch R, Ros E, Salas-Salvado J, Covas M, Corella D, Aros F, et al. Primary prevention of cardiovascular disease with a mediterranean diet. N Engl J Med. 2013;368(14):1279-90.

21. Esposito K, Maiorino M, Ciotola M, Di Palo C, Scognamiglio P, Gicchino M, et al. Effects of a mediterranean-style diet on the need for antihyperglycemic drug therapy in patients with newly diagnosed type 2 diabetes: a randomized trial. Ann Intern Med. 2009;151(5):306-14. http://dx.doi.org/10.7326/0003-4819151-5-200909010-00004

22. Estruch R, Martinez-Gonzalez M, Corella D, Salas-Salvado J, Ruiz-Gutierrez V, Covas M, et al. Effects of a mediterranean-style diet on cardiovascular risk factors: a randomized trial. Ann Intern Med. 2006;145(1):1-11. http://dx.doi.org/10.7326/0003-4819-145-1-200607040-00004.

23. Perez-Martinez P, Ordovas J, Garcia-Rios A, Delgado-Lista J, Delgado-Casado $\mathrm{N}$, Cruz-Teno C, et al. Consumption of diets with different type of Fat influences triacylglycerols-rich lipoproteins particle number and size during the postprandial state. Nutr Metab Cardiovasc Dis. 2011;21 (1):39-45. http://dx.doi.org/10.1016/J.Numecd.2009.07.008.

24. Barona J, Jones J, Kopec R, Comperatore M, Andersen C, Schwartz S, et al. A mediterranean-style Low-glycemic-load diet increases plasma carotenoids and decreases Ldl oxidation in women with metabolic 
syndrome. J Nutr Biochem. 2012;23(6):609-15. http://dx.doi.org/10.1016/ J.Jnutbio.2011.02.016.

25. Djuric $Z$. The mediterranean diet: effects on proteins that mediate fatty acid metabolism in the colon. Nutr Rev. 2011;69(12):730-44. http://dx.doi.org/10.1111/J.1753-4887.2011.00439.X.

26. Djuric Z, Ren J, Blythe J, Vanloon G, Sen A. A mediterranean dietary intervention in healthy american women changes plasma carotenoids and fatty acids in distinct clusters. Nutr Res. 2009;29(3):156-63. http://dx.doi.org/10.1016/J.Nutres.2009.03.001.

27. Toobert D, Glasgow R, Strycker L, Barrera M, Raddliffe J, Wander R, et al. Biologic and quality-of-life outcomes from the mediterranean lifestyle program: a randomized clinical trial. Diabetes Care. 2003;26(8):2288-93. http://dx.doi.org/10.2337/Diacare.26.8.2288.

28. Tuttle K, Shuler L, Packard D, Milton J, Daratha K, Bibus D, et al. Comparison of Low-Fat versus mediterranean-style dietary intervention after first myocardial infarction (from the heart institute of spokane diet intervention and evaluation trial). Am J Cardiol. 2008;101(11):1523-30. http://dx.doi.org/10.1016/J.Amjcard.2008.01.038.

29. Shai I, Schwarzfuchs D, Henkin Y, Shahar D, Witkow S, Greenberg I, et al. Weight loss with a Low-carbohydrate, mediterranean, or Low-Fat diet. N Engl J Med. 2008;359(3):229-41. http://dx.doi.org/10.1056/ Nejmoa0708681.

30. Mozaffarian D, Ludwig D. Dietary guidelines in the 21st century-a time for food. Jama. 2010;304(6):681-2. http://dx.doi.org/10.1001/Jama.2010.1116.

31. Harvey J, Ogden D. Obesity treatment in disadvantaged population groups: where Do We stand and what Can We Do? Prev Med. 2014;68:71-5. http://dx.doi.org/10.1016/J.Ypmed.2014.05.015.

32. Kumanyika S, Whitt-Glover M, Haire-Joshu D. What works for obesity prevention and treatment in black Americans? research directions. Obes Rev. 2014;15 Suppl 4:204-12. http://dx.doi.org/10.1111/Obr.12213.

33. Wingo B, Carson T, Ard J. Differences in weight loss and health outcomes among African americans and whites in multicentre trials. Obes Rev. 2014;15 Suppl 4:46-61. http://dx.doi.org/10.1111/Obr.12212.

34. Samuel-Hodge C, Johnson C, Braxton D, Lackey M. Effectiveness of diabetes prevention program translations among African Americans. Obes Rev. 2014;15 Suppl 4:107-24. http://dx.doi.org/10.1111/Obr.12211.

35. North Carolina Department Of Health And Human Services Division Of Public Health, State Center For Health Statistics. North Carolina Statewide And County Trends In Key Health Indicators: Lenoir County. February 2013. [http://www.Schs.State.Nc.Us/Schs/Data/Trends/Pdf/Lenoir.Pdf]. Accessed 01 Aug 2014

36. Centers For Disease Control And Prevention. Division For Heart Disease And Stroke Prevention: Interactive Atlas. [http://nccd.cdc.gov/dhdspatlas/]. Accessed 01 Aug 2014

37. Pitts S, Vu M, Garcia B, Mcguirt J, Braxton D, Hengel C, et al. A community assessment to inform a multilevel intervention to reduce cardiovascular disease risk and risk disparities in a rural community. Fam Community Health. 2013;36(2):135-46. http://dx.doi.org/10.1097/Fch. 0b013e31828212be.

38. Halladay J, Donahue K, Hinderliter A, Cummings D, Cene C, Miller C, et al. The heart healthy lenoir project-an intervention to reduce disparities in hypertension control: study protocol. BMC Health Serv Res. 2013;13:441. http://dx.doi.org/10.1186/1472-6963-13-441.

39. Keyserling T, Samuel Hodge C, Jilcott S, Johnston L, Garcia B, Gizlice Z, et al. Randomized trial of a clinic-based, community-supported, lifestyle intervention to improve physical activity and diet: the North Carolina enhanced wisewoman project. Prev Med. 2008;46(6):499-510. http://dx.doi.org/10.1016/J.Ypmed.2008.02.011.

40. Samuel-Hodge C, Johnston L, Gizlice Z, Garcia B, Lindsley S, Bramble K, et al. Randomized trial of a behavioral weight loss intervention for Low-income women: the weight wise program. Obesity (Silver Spring). 2009;17(10):1891-9. http://dx.doi.org/10.1038/Oby.2009.128.

41. Samuel-Hodge C, Garcia B, Johnston L, Gizlice Z, Ni A, Cai J, et al. Translation of a behavioral weight loss intervention for Mid-life, Lowincome women in local health departments. Obesity (Silver Spring). 2013;21(9):1764-73. http://dx.doi.org/10.1002/Oby.20317.

42. Keyserling T, Sheridan S, Draeger L, Finkelstein E, Gizlice Z, Kruger E, et al. A comparison of live counseling with a Web-based lifestyle and medication intervention to reduce coronary heart disease risk: a randomized clinical trial. Jama Intern Med. 2014;174:1144-57. http://dx.doi.org/10.1001/Jamainternmed.2014.1984.
43. Shephard R. Qualified fitness and exercise professionals and exercise prescription: evolution of the Par-Q and Canadian aerobic fitness test. J Phys Act Health. 2015;12(4):454-61. http://dx.doi.org/10.1123/Jpah. 2013-0473.

44. Ammerman A, Haines P, DeVellis R, Strogatz D, Keyserling T, Simpson Jr R, et al. A brief dietary assessment to guide cholesterol reduction in Lowincome individuals: design and validation. J Am Diet Assoc. 1991;91(11):1385-90.

45. Ammerman A, DeVellis B, Haines P, Keyserling T, Carey T, DeVellis R, et al. Nutrition education for cardiovascular disease prevention among Low income populations: description and pilot evaluation of a physician-based model. Patient Educ Couns. 1992;19(1):5-18.

46. Ammerman A, Keyserling T, Atwood J, Hosking J, Zayed H, Krasny C. A randomized controlled trial of a public health nurse directed treatment program for rural patients with high blood cholesterol. Prev Med. 2003;36(3):340-51. http://dx.doi.org/10.1016/50091-7435(02)00042-7.

47. Keyserling T, Ammerman A, Davis C, Chen Mok M, Garrett J, Simpson Jr R. A randomized controlled trial of a physician-directed treatment program for Low-income patients with high blood cholesterol: the southeast cholesterol project. Arch Fam Med. 1997;6(2):135-45.

48. Keyserling T, Ammerman A, Atwood J, Hosking J, Krasny C, Zayed H, et al. A cholesterol intervention program for public health nurses in the rural southeast: description of the intervention, study design, and baseline results. Public Health Nurs. 1999;16(3):156-67. http://dx.doi.org/10.1046/J.1525-1446.1999.00156.X.

49. Jakobsen M, O'reilly E, Heitmann B, Pereira M, Balter K, Fraser G, et al. Major types of dietary Fat and risk of coronary heart disease: a pooled analysis of 11 cohort studies. Am J Clin Nutr. 2009;89(5):1425-32. http//dx.doi.org/10.3945/Ajcn.2008.27124.

50. Lichtenstein A, Appel L, Brands M, Carnethon M, Daniels S, Franch H, et al. Diet and lifestyle recommendations revision 2006: a scientific statement from the American heart association nutrition committee. Circulation. 2006;114(1):82-96. http://dx.doi.org/10.1161/Circulationaha.106.176158.

51. Mozaffarian D, Micha R, Wallace S. Effects on coronary heart disease of increasing polyunsaturated Fat in place of saturated Fat: a systematic review and meta-analysis of randomized controlled trials. Plos Med. 2010;7(3):E1000252. http://dx.doi.org/10.1371/Journal.Pmed.1000252.

52. Oh K, Hu F, Manson J, Stampfer M, Willett W. Dietary Fat intake and risk of coronary heart disease in women: 20 years of follow-Up of the Nurses' health study. Am J Epidemiol. 2005;161(7):672-9. http://dx.doi.org/10.1093/Aje/Kwi085.

53. Siri-Tarino P, Sun Q, Hu F, Krauss R. Meta-analysis of prospective cohort studies evaluating the association of saturated Fat with cardiovascular disease. Am J Clin Nutr. 2010;91(3):535-46. http://dx.doi.org/10.3945/Ajcn.2009.27725.

54. Sofi F, Abbate R, Gensini G, Casini A. Accruing evidence on benefits of adherence to the mediterranean diet on health: an updated systematic review and meta-analysis. Am J Clin Nutr. 2010;92(5):1189-96. http://dx.doi.org/10.3945/Ajen.2010.29673.

55. Sofi F, Cesari F, Abbate R, Gensini G, Casini A. Adherence to mediterranean diet and health status: meta-analysis. BMJ. 2008;337:A1344. http://dx.doi.org/10.1136/Bmj.A1344.

56. Mozaffarian D, Rimm E. Fish intake, contaminants, and human health: evaluating the risks and the benefits. Jama. 2006;296(15):1885-99. http://dx.doi.org/10.1001/Jama.296.15.1885.

57. Clark N, Janz N, Dodge J, Mosca L, Lin X, Long Q, et al. The effect of patient choice of intervention on health outcomes. Contemp Clin Trials. 2008;29(5): 679-86. http://dx.doi.org/10.1016/J.Cct.2008.04.002.

58. Janevic M, Janz N, Dodge J, Lin X, Pan W, Sinco B, et al. The role of choice in health education intervention trials: a review and case study. Soc Sci Med. 2003;56(7):1581-94.

59. Sheridan S, Draeger L, Pignone M, Sloane P, Samuel-Hodge C, Finkelstein E, et al. Designing and implementing a comparative effectiveness study of Two strategies for delivering high quality Chd prevention: methods and participant characteristics for the heart to health study. Contemp Clin Trials. 2013;36(2):394-405. http://dx.doi.org/10.1016/J.Cct.2013.07.013.

60. Samuel-Hodge C, Garcia B, Johnston L, Kraschnewski J, Gustafson A, Norwood A, et al. Rationale, Design, And Sample Characteristics Of A Practical Randomized Trial To Assess A Weight Loss Intervention For Low-Income Women: The Weight-Wise li Program. Contemp Clin Trials. 2012;33(1):93-103. http://dx.doi.org/10.1016/J.Cct.2011.08.009.

61. Steinberg D, Tate D, Bennett G, Ennett S, Samuel-Hodge C, Ward D. Daily self-weighing and adverse psychological outcomes: a randomized 
controlled trial. Am J Prev Med. 2014;46(1):24-9. http://dx.doi.org/10.1016/J. Amepre.2013.08.006.

62. Jilcott S, Keyserling T, Samuel-Hodge C, Johnston L, Gross M, Ammerman A. Validation of a brief dietary assessment to guide counseling for cardiovascular disease risk reduction in an underserved population. J Am Diet Assoc. 2007;107(2):246-55. http://dx.doi.org/10.1016/J.Jada.2006.11.006.

63. Block $G$, Gillespie C, Rosenbaum E, Jenson C. A rapid food screener to assess Fat and fruit and vegetable intake. Am J Prev Med. 2000;18(4):284-8. http://dx.doi.org/10.1016/S0749-3797(00)00119-7.

64. Kraschnewski J, Gold A, Gizlice Z, Johnston L, Garcia B, Samuel-Hodge C, et al. Development and evaluation of a brief questionnaire to assess dietary Fat quality in Low-income overweight women in the southern United States. J Nutr Educ Behav. 2013;45(4):355-61. http://dx.doi.org/10.1016/J. Jneb.2012.10.008.

65. Giles-Corti B, Timperio A, Cutt H, Pikora T, Bull F, Knuiman M, et al. Development of a reliable measure of walking within and outside the local neighborhood: Reside's neighborhood physical activity questionnaire. Prev Med. 2006;42(6):455-9. http://dx.doi.org/10.1016/J.Ypmed.2006.01.019.

66. Jones S, Evenson K, Johnston L, Trost S, Samuel-Hodge C, Jewell D, et al. Psychometric properties of the modified reside physical activity questionnaire among Low-income overweight women. J Sci Med Sport. 2014:18(1):37-42. http://dx.doi.org/10.1016/J.Jsams.2013.12.007.

67. Rosamond W, Ammerman A, Holliday J, Tawney K, Hunt K, Keyserling T, et al. Cardiovascular disease risk factor intervention in Low-income women: the North Carolina wisewoman project. Prev Med. 2000;31(4):370-9. http://dx.doi.org/10.1006/Pmed.2000.0726.

68. Ammerman A, Washington C, Jackson B, Weathers B, Campbell M, Davis G, et al. The praise! project: a church-based nutrition intervention designed for cultural appropriateness, sustainability. And Diffusion Health Promot Pract. 2002;3(2):286-301

69. Us Preventive Services Task Force. Obesity In Adults: Screening And Management. 2012. [http://www.Uspreventiveservicestaskforce.Org/Uspstf/ Uspsobes.Htm]. Accessed 14 Sept 2015.

70. Booth H, Prevost T, Wright A, Gulliford M. Effectiveness of behavioural weight loss interventions delivered in a primary care setting: a systematic review and meta-analysis. Fam Pract. 2014;31(6):643-53. http://dx.doi.org/10.1093/Fampra/Cmu064.

71. Gudzune K, Doshi R, Mehta A, Chaudhry Z, Jacobs D, Vakil R, et al. Efficacy of commercial weight-loss programs: an updated systematic review. Ann Intern Med. 2015;162(7):501-12. http://dx.doi.org/10.7326/M14-2238.

72. Hartmann-Boyce J, Johns D, Jebb S, Summerbell C, Aveyard P. Behavioural weight management programmes for adults assessed by trials conducted in everyday contexts: systematic review and meta-analysis. Obes Rev. 2014:15(11):920-32. http://dx.doi.org/10.1111/Obr.12220.

73. North Carolina Department Of Health And Human Services Division Of Public Health, State Center For Health Statistics. Annual Survey Results: Behavioral Risk Factor Surveillance System (Brfss). [http://www.Schs.State.Nc. Us/Data/Brfss/Survey.Htm]. Accessed 07 Apr 2016.

\section{Submit your next manuscript to BioMed Central and we will help you at every step:}

- We accept pre-submission inquiries

- Our selector tool helps you to find the most relevant journal

- We provide round the clock customer support

- Convenient online submission

- Thorough peer review

- Inclusion in PubMed and all major indexing services

- Maximum visibility for your research

Submit your manuscript at www.biomedcentral.com/submit

) Biomed Central 